\title{
REVIEWS \\ Precise Synthesis of Regular and Asymmetric Star Polymers and Densely Branched Polymers with Starlike Structures by Means of Living Anionic Polymerization
}

\author{
Akira Hirao, ${ }^{\dagger}$ Mayumi HaYashi, Yui ToKuda, Naoki Haraguchi, \\ Tomoya HigashiHARA, and Sang Woog RYU \\ Polymeric and Organic Materials Department, Graduate School of Science and Technology, Tokyo Institute of \\ Technology, 2-12-1 Ohokayama, Meguro-ku, Tokyo 152-8552, Japan
}

(Received May 27, 2002; Accepted August 6, 2002)

\begin{abstract}
The subject of this review is to present new synthetic methodologies recently developed by us, which are applicable to both regular and asymmetric star polymers with well-defined architectures. The first methodology involves the coupling reaction of a variety of living anionic polymers of styrene, $\alpha$-methylstyrene, isoprene, tert-butyl methacrylate, and ethylene oxide with novel chain-end- and in-chain-functionalized polymers with a definite number of benzyl halide moieties intentionally designed as polymeric coupling agents. In the second methodology, we propose a new concept based on iterative approach, with which star polymers can be successively and, in principle, unlimitedly synthesized by repeating the iterative reaction sequence. Finally, a convenient synthesis of densely branched polymers with starlike structures is presented by the quantitative coupling reaction of living anionic polymers with reactive benzyl halide-functionalized backbone polymers based on a grafting-onto method.

KEY WORDS Star Polymer / Asymmetric Star Polymer / Living Anionic Polymerization / Iterative Methodology / Polymeric Coupling Agent / 1,1-Diphenylethylene Derivative /
\end{abstract}

Star polymers are branched polymers in which more than three linear polymer chains are linked together at one end of each chain by a central core or a single branch. They have physical properties in bulk, melt, and solution quite distinct from linear analogues. For this reason, star polymers have been widely studied from both synthetic and theoretical points of view. ${ }^{1-9}$ It is of course essential to use star polymers with welldefined structures for evaluating fundamental understanding regarding the effect of chain branching on such physical properties.

At the present time, the most successful methodologies for the synthesis well-defined regular star polymers have been developed mainly based on coupling reactions of living anionic polymers of styrene and 1,3-dinene monomers with multifunctional chlorosilane compounds as electrophilic coupling agents. A variety of star polymers with a definite number of three to eighteen arms have been synthesized. ${ }^{10-19}$ Furthermore, the successful syntheses of the 32-, 64-, and even 128 -arm star polymers by using specially designed carbosilane dendrimers have been reported so far. ${ }^{20,21}$

Currently, great attention has been paid to more complex asymmetric star polymers whose arms differ in molecular weight and chemical composition, since star polymers of this type are expected to exhibit interesting and unique physical performance originated from their

${ }^{\dagger}$ To whom correspondence should be addressed. branched architectures as well as heterophase structures. ${ }^{22-33}$ Synthesis of asymmetric star polymers is generally more difficult than that of regular star polymers. In the synthesis of regular star polymers, for example, their arms can be simultaneously introduced by one reaction. On the other hand, two or more highyielding reactions are required for introducing different arms in molecular weight and chemical composition of asymmetric star polymers. Furthermore, isolation of intermediate polymers is often needed in each reaction step. Therefore, different synthetic methodologies are required for the synthesis of asymmetric star polymers.

Most of well-defined asymmetric star polymers have now been synthesized mainly by the following two methodologies: The first one involves the successive linking reactions of living anionic polymers with multifunctional chlorosilanes by utilizing different reactivities of living anionic polymers toward the $\mathrm{Si}-\mathrm{Cl}$ bonds. Various asymmetric stars of the type such as $\mathrm{AB}_{2}, \mathrm{AB}_{3}, \mathrm{ABC}, \mathrm{ABCD}$, and $\mathrm{A}_{8} \mathrm{~B}_{8}$ usually consisting of polystyrene, poly(1,3-butadiene), and polyisoprene segments have been synthesized. ${ }^{34-46}$ The second methodology involves the coupling reaction of non-polymerizable macromonomers with living polymers, followed by initiating the polymerization of additional monomers. By developing this methodology, the synthesis of $\mathrm{ABC}$ and $\mathrm{A}_{2} \mathrm{~B}_{2}$ star polymers containing poly(alkyl methacrylate) segments have been real- 
ized. ${ }^{47-54}$ In addition, some other methods that are similar in part to the above-mentioned methods have been reported ${ }^{55-64}$ Hadjichristidis and his coworkers have well reviewed the recent advances of these synthetic methodologies. ${ }^{65-67}$ Some other excellent reviews on the same subject have also recently appeared. ${ }^{51,68-74}$

Several research groups have widely studied the methodology in which difunctional monomers such as divinylbenzene and ethyleneglycol dimethacrylate are reacted with anionic species present at the initiation or termination stages of living polymerization to synthesize star polymers. ${ }^{75-94}$ Since well control of such reactions is difficult, the core parts of the resulting star polymers have always some distributions. Accordingly, the method is less suitable for the synthesis of welldefined star polymers, but technologically important to synthesize star polymers in industrial scale.

Several successful synthetic examples of asymmetric star polymers with well-defined architectures have so far been reported since 1988 despite their synthetic difficulties. However, structural and architectural variation of asymmetric star polymers are still limited in synthetic points of view and a new development of general and systematic methodologies is desired even at the present time.

In this article, we would like to present two new synthetic methodologies based on living anionic polymerization recently developed by us, which are applicable to both regular and asymmetric star polymers with well-defined architectures. In addition, a convenient synthesis of star polymers based on "grafting onto method" is also described. In the first methodology, various novel chain-end- and in-chain-functionalized polymers with a definite number of benzyl halide moieties are synthesized and employed as polymeric coupling agents instead of low molecular weight coupling agents in the reaction of living anionic polymers for the synthesis of star polymers. These functionalized polymers can be intentionally designed in number and placement of benzyl halide moiety as well as in chain structure. Accordingly, a variety of regular and asymmetric star polymers can be synthesized by the combination of living anionic polymers with such functionalized polymeric coupling agents. In the second methodology, we propose a new concept based on iterative approach, with which star polymers can be successively and, in principle, unlimitedly synthesized. The success of this methodology strongly depends upon how many times of the iterative reaction sequence can be repeated.

Finally, we present the synthesis of densely branched polymers by the quantitative coupling reaction of living anionic polymers with reactive backbone polymers based on "grafting-onto" method. In the densely branched polymers with longer branches relative to backbone polymers, the core dimensions are smaller than those of the outer branches. Therefore, such polymers should be closer to starlike macromolecules rather than molecular brush or comblike polymers. Their arm numbers exactly correspond to the reaction sites of backbone polymers. Thus, the methodology for the synthesis of densely branched polymers also offers a convenient synthesis of star polymers with many arms.

The star polymers herein synthesized are precisely controlled in chain length of arm segment and welldefined in architecture, since almost all the reaction steps can be well controlled and living anionic polymers are always used as arm segments and cores. Synthetic possibility as well as generality and versatility of such methodologies will be discussed.

\section{SYNTHESIS OF STAR POLYMERS USING BENZYL HALIDE-FUNCTIONALIZED POLYMERS AS COUPLING AGENTS}

For the synthesis of both regular and asymmetric star polymers, we have recently developed a new methodology using various chain-end- and inchain-functionalized polymers with a definite number of benzyl halide moieties. ${ }^{95-98}$ These benzyl halidefunctionalized polymers are used as polymeric coupling agents in the reaction of living anionic polymers.

The synthetic outlines are illustrated in Scheme 1. If the number $(n)$ of benzyl halide moieties are placed at a chain-end, regular star polymers of the type $\mathrm{A}_{n+1}$ and asymmetric stars of the types $\mathrm{AA}_{n}^{\prime}$ and $\mathrm{AB}_{n}$ can be synthesized from the same functionalized polymer (A) only by changing the living polymer to be reacted in the coupling reaction. In the case where benzyl halides are placed at the middle of the chain, a series of asymmetric star polymers of $\mathrm{A}_{2} \mathrm{~A}_{n}^{\prime}$ and $\mathrm{A}_{2} \mathrm{~B}_{n}$ can be synthesized. Regular stars of the type $\mathrm{A}_{n+2}$ are also obtained by using the same living polymer as the functionalized polymer in main chain. Furthermore, it is possible to synthesize $\mathrm{ABC}_{n}$ type asymmetric star polymers if benzyl halides are placed between two blocks of the block copolymer. Thus, various regular and asymmetric star polymers can be synthesized by intentionally designing the structures of benzyl halide-functionalized polymers and selecting living polymers to be coupled.

Synthesis of Chain-End- and In-Chain-Functionalized Polymers with a Definite Number of Benzyl Halide Moieties

We have recently developed general and versatile methodologies for the synthesis of the title benzyl halide-functionalized polymers. ${ }^{72,99,100}$ Although 


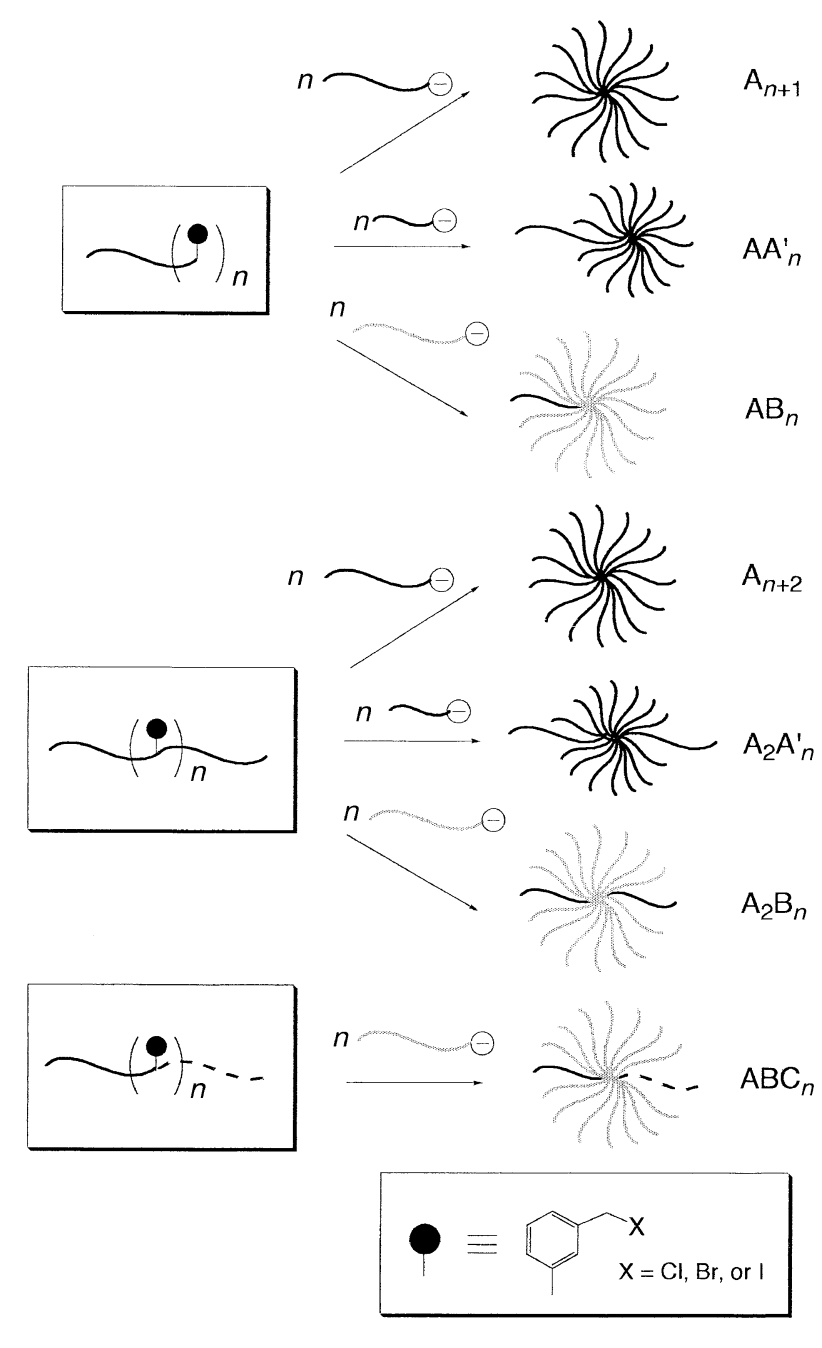

Scheme 1.

the direct introduction of benzyl halide function into living anionic polymers would be most effective, it is not possible since benzyl halide functions are highly reactive and incompatible with living anionic polymers. Instead, we have at first employed the anion-stable methoxymethylphenyl group as a precursor of the benzyl chloride function during the reactions of living anionic polymers and subsequently transformed the methoxymethylphenyl groups introduced into benzyl chlorides. Representative synthetic routes are illustrated in Scheme 2. The first reaction step is to introduce a definite number of methoxymethylphenyl groups at chain ends or in chains by diverse modes of addition reactions of 1(3-methoxymethylphenyl)-1-phenylethylene (1), 1,1bis(3-methoxymethylphenyl)ethylene (2), and/or their derivatives to living anionic polymers. In the second step, the methoxymethylphenyl groups thus introduced are quantitatively transformed into benzyl chloride moieties with $\mathrm{BCl}_{3}$.

Chain-end-functionalized polystyrenes with one and two benzyl chloride moieties were synthesized by the addition reaction of $\mathbf{1}$ and $\mathbf{2}$ to polystyryllithium in THF at $-78^{\circ} \mathrm{C}$ for $0.5 \mathrm{~h}$, followed by transformation reaction with $\mathrm{BCl}_{3}$ in $\mathrm{CH}_{2} \mathrm{Cl}_{2}$ at $0^{\circ} \mathrm{C}$ for $10 \mathrm{~min}$. Both the reactions quantitatively proceeded to afford the expected chain-end-functionalized polystyrenes with one and two benzyl chloride moieties. For the synthesis of chain-end-functionalized polystyrenes with three and four benzyl chloride moieties, a polystyrene with two methoxymethylphenyl and one 4-bromobutyl termini was first prepared as a precursory polymer by the reaction of polystyryllithium with $\mathbf{2}$, followed by treatment with a 5-fold excess of 1,4-dibromobutane. ${ }^{101}$ The resulting precursory polymer was then reacted with the functionalized 1,1-diphenylalkyl anion prepared from $s e c-\mathrm{BuLi}$ and either $\mathbf{1}$ or $\mathbf{2}$ to quantitatively introduce three or four methoxymethylphenyl groups. These groups were then transformed into three and four benzyl chloride moieties by treatment with $\mathrm{BCl}_{3}$.

In-chain-functionalized polystyrene with two or four benzyl chloride moieties could be synthesized by the reaction of the same precursory polymer with either polystyryllithium or polystyryllithium end-capped with 2 followed by transformation with $\mathrm{BCl}_{3}$. In each of both polymers, the benzyl chloride moieties introduced were placed at the middle of the polymer chain, since polystyryllithium was almost the same in molecular weight as the precursory polymer. It is of course possible to place benzyl chloride moieties at essentially any desired position in a polymer chain simply by changing molecular weights of both polystyryllithium and the precursory polymer.

Chain-functionalized poly(styrene- $\left.d_{8}\right) \mathrm{s}, \quad \operatorname{poly}(\alpha-$ methylstyrene)s, and poly(4-methylstyrene)s with a definite number of benzyl chloride moieties could also be synthesized in similar fashions. In-chainfunctionalized block copolymer, polystyrene-block$\operatorname{poly}(\alpha$-methylstyrene), with two or four benzyl chloride moieties between two blocks could also be synthesized by the reaction of the precursory polymers with either $\operatorname{poly}(\alpha$-methylstyryllithium) or $\operatorname{poly}(\alpha$-methylstyryllithium) end-capped with 2 .

For the synthesis of chain-functionalized polystyrenes with six or more benzyl chloride moieties, a new functionalized derivative, 1,10-dichloro-4,4,7,7tetra(3-methoxymethylphenyl)decane (3) was prepared by the dimerization of $\mathbf{2}$ with potassium naphthalenide followed by treatment with a 1.2-fold excess of 1bromo-3-chloropropane. ${ }^{100}$ The latter substitution reaction was observed to undergo completely selective monoalkylation with the bromide part as illustrated in Scheme 3.

In order to synthesize chain-end-functionalized polystyrenes with six and eight benzyl chloride moieties, two functionalized precursory polymers with four 


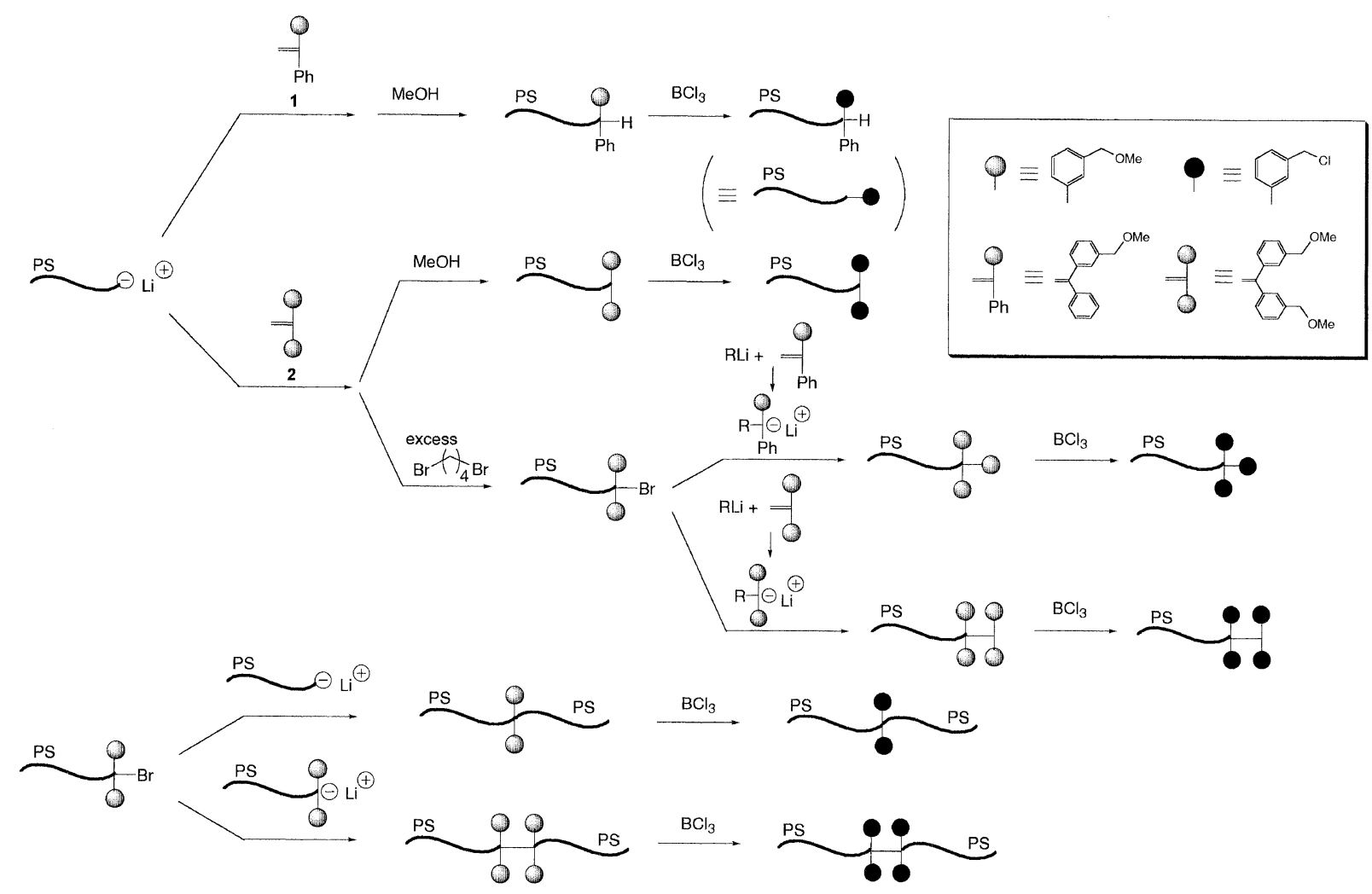

Scheme 2.

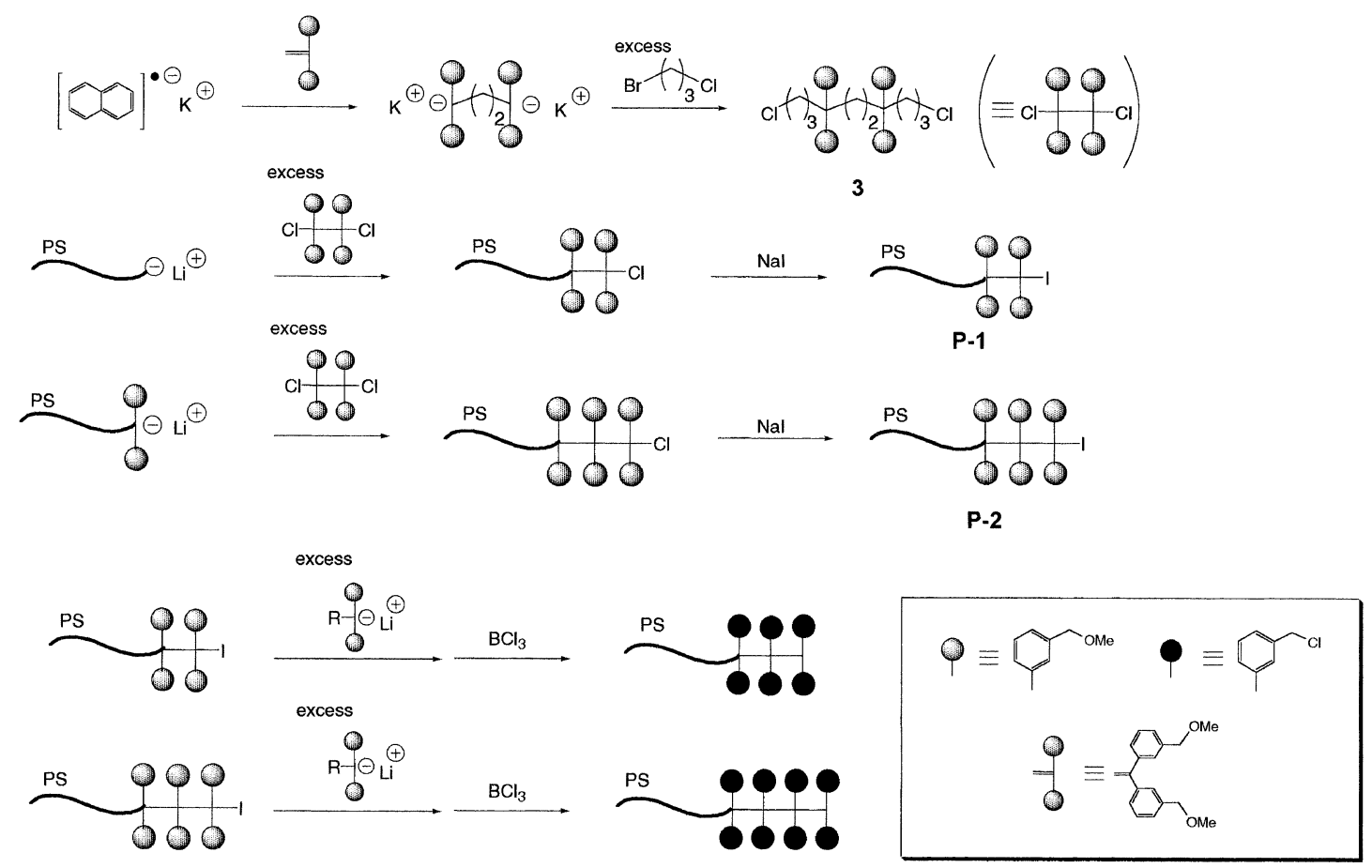

Scheme 3.

and six methoxymethylphenyl and one 3-chloropropyl termini were prepared by reacting a 2.0-fold excess of 3 with polystyryllithium and polystyryllithium endcapped with 2 . The expected precursory polymers were usually obtained in 75-93\% yields along with the formation of undesirable dimeric products formed from two equivalents of the living polymers and $\mathbf{3}$ and therefore isolated by fractionation with SEC or fractional precipitation to remove the dimers. The isolated polymers showed symmetrical monomodal SEC peaks with narrow molecular weight distributions and quantitative functionalization degrees within analytical limits. The terminal chlorides of the precursory polymers were then converted to more reactive iodides by treat- 


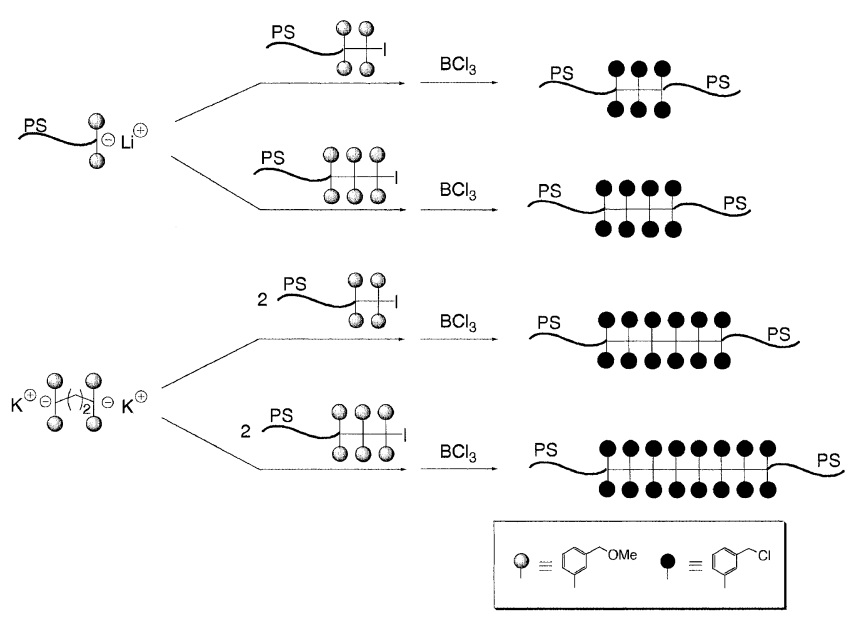

Scheme 4.

ing them with $\mathrm{NaI}$ in acetone. The resulting iodinated polymers, $\mathbf{P}-\mathbf{1}$ and $\mathbf{P}-\mathbf{2}$, were reacted with the functionalized 1,1-diphenylalkyl anion prepared from 2 and sec$\mathrm{BuLi}$ to afford the expected chain-end-functionalized polystyrenes with six and eight benzyl chloride moieties after treatment with $\mathrm{BCl}_{3}$ (see also Scheme 3).

Using P-1 and P-2, in-chain-functionalized polystyrenes with six, eight, twelve, and sixteen benzyl chloride moieties were synthesized according to the procedures as illustrated in Scheme 4. In-chainfunctionalized polystyrene with six or eight benzyl chloride moieties was obtained by the reaction of either $\mathbf{P}-\mathbf{1}$ or $\mathbf{P}-\mathbf{2}$ with polystyryllithium end-capped with 2 , followed by treatment with $\mathrm{BCl}_{3}$. In-chainfunctionalized polystyrenes with twelve and sixteen benzyl chloride moieties were synthesized by the coupling reaction of two equivalents of $\mathbf{P}-\mathbf{1}$ and $\mathbf{P}-\mathbf{2}$ with the functionalized dimeric dianion prepared from 2 and potassium naphthalenide. All of the reactions efficiently proceeded to afford the expected in-chainfunctionalized polymers in almost quantitative yields. The precursory polymers were usually used in slight excesses in the reactions in order to force the reactions to completion and therefore removed by fractional precipitation or fractionation with SEC.

The representative results of all chain-functionalized polystyrenes with benzyl chloride moieties thus synthesized are listed in Table I. As can be seen, the resulting polymers possess sharp, monomodal SEC distributions, predictable molecular weights, and quantitative degrees of functionalization within analytical limits.

It should be mentioned that a small high molecular weight polymer $(\sim 5 \%)$, which seemed double the molecular weight of the objective polymer, was often, although not always, formed in transformation reaction with $\mathrm{BCl}_{3} .{ }^{99}$ Intermolecular polymer coupling by a Friedel-Crafts alkylation reaction catalyzed with $\mathrm{BCl}_{3}$ may be the most likely
Table I. Synthesis of chain-functionalized polystyrenes with benzyl chloride moieties

\begin{tabular}{|c|c|c|c|c|c|}
\hline \multicolumn{2}{|c|}{$M_{\mathrm{n}}\left(\mathrm{kg} \mathrm{mol}^{-1}\right)$} & \multirow{2}{*}{$\frac{M_{\mathrm{w}} / M_{\mathrm{n}}}{\mathrm{SEC}}$} & \multicolumn{3}{|c|}{ Benzyl chloride functionality } \\
\hline Calcd & SEC & & Placement & Calcd & ${ }^{1} \mathrm{H}$ NMR \\
\hline 2.70 & 2.80 & 1.05 & End & 1 & $1.0_{0}$ \\
\hline 5.20 & 5.14 & 1.04 & End & 2 & $2.0_{0}$ \\
\hline 6.50 & 6.24 & 1.09 & End & 3 & $3.1_{0}$ \\
\hline 6.53 & 6.91 & 1.09 & End & 4 & $3.9_{9}$ \\
\hline 3.50 & 3.70 & 1.06 & End & 6 & $5.9_{0}$ \\
\hline 5.24 & 5.80 & 1.04 & End & 8 & $8.2_{4}$ \\
\hline 9.61 & 10.4 & 1.01 & In & 6 & $5.8_{8}$ \\
\hline 7.70 & 7.41 & 1.02 & In & 8 & $8.0_{0}$ \\
\hline 12.0 & 12.0 & 1.03 & In & 12 & 12.0 \\
\hline 12.2 & 10.7 & 1.04 & In & 16 & 15.3 \\
\hline
\end{tabular}

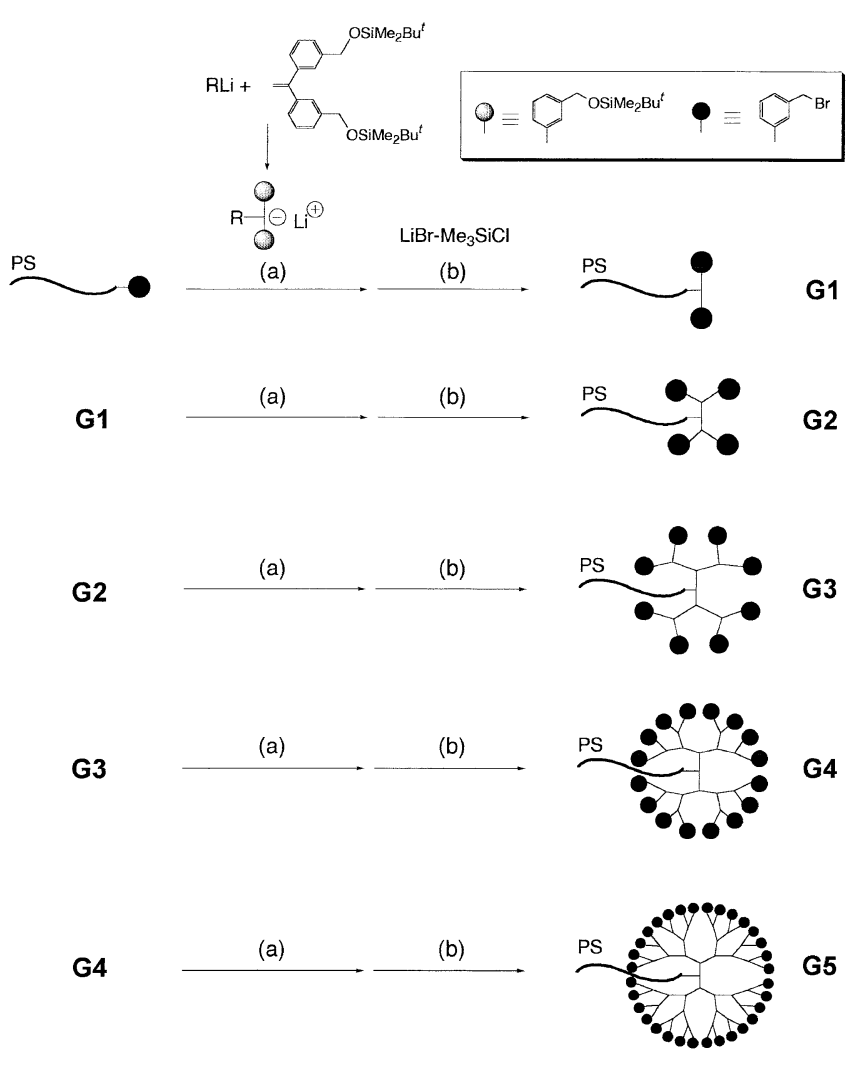

Scheme 5.

cause for the high molecular weight polymer formation. The high molecular weight polymers, if formed, were readily and completely removed by fractionation with SEC. The silyl derivative of 2, 1,1-bis(3tert-butyldimethylsilyloxymethylphenyl)ethylene (4), can also be used in the same addition reactions under the identical conditions. The introduced tert-butyldimethylsilyloxymethylphenyl groups can be transformed into benzyl chloride moieties with $\mathrm{BCl}_{3}$. Furthermore, they can be transformed into benzyl bromide and benzyl iodide moieties by treatment with $\left(\mathrm{CH}_{3}\right)_{3} \mathrm{SiCl}-\mathrm{LiBr}$ and $\left(\mathrm{CH}_{3}\right)_{3} \mathrm{SiCl}-\mathrm{NaI}$, respectively. Fortunately, these transformation reactions cleanly and quantitatively proceeded without undesirable polymer coupling reaction observed in the reaction of 
Table II. Synthesis of chain-end-functionalized polystyrenes with two, four, eight, sixteen, and thirty-two benzyl bromide moieties

\begin{tabular}{|c|c|c|c|c|c|c|c|}
\hline \multirow{2}{*}{ Type } & \multicolumn{3}{|c|}{$M_{\mathrm{n}}\left(\mathrm{kg} \mathrm{mol}{ }^{-1}\right)$} & \multirow{2}{*}{$\frac{M_{\mathrm{w}} / M_{\mathrm{n}}}{\mathrm{SEC}}$} & \multicolumn{3}{|c|}{ Benzyl bromide functionality } \\
\hline & Calcd & SEC & VPO & & Calcd & ${ }^{1} \mathrm{H}$ NMR & E.A. $^{a}$ \\
\hline G1 & 4.79 & 4.23 & 4.80 & 1.04 & 2 & $2.0_{0}$ & $2.1_{4}$ \\
\hline G2 & 5.47 & 4.96 & 5.42 & 1.04 & 4 & $3.9_{2}$ & $4.0_{9}$ \\
\hline G3 & 6.85 & 5.60 & 6.78 & 1.03 & 8 & $8.0_{8}$ & $8.3_{3}$ \\
\hline G4 & 9.59 & 7.05 & 9.64 & 1.04 & 16 & $15_{9}$ & $15_{8}$ \\
\hline G5 & 15.0 & 8.54 & 14.8 & 1.03 & 32 & $32_{0}$ & $32_{1}$ \\
\hline
\end{tabular}

${ }^{\mathrm{a}}$ Elemental analysis.

methoxymethylphenyl group with $\mathrm{BCl}_{3}$. Therefore, in certain cases, benzyl bromide-functionalized polymers are used instead of the benzyl chloride ones.

Very recently, an alternative methodology via an iterative approach has been developed for chain-endfunctionalized polymers with benzyl bromide moieties as illustrated in Scheme 5. ${ }^{102-104}$ In this methodology, only two sets of the reactions are needed for the entire iterative synthetic sequence: a coupling reaction of the terminal benzyl bromide moieties with the functionalized 1,1-diphenylalkyl anion prepared from 4 and sec-BuLi and a transformation reaction of the tertbutyldimethylsilyloxymethylphenyl groups into benzyl bromide moieties by treatment with $\mathrm{LiBr}-\left(\mathrm{CH}_{3}\right)_{3} \mathrm{SiCl}$. Starting from a chain-end-functionalized polystyrene with one benzyl bromide moiety, the two reactions in the iteration were repeated five times. The results are summarized in Table II.

As shown in Figure 1, all of the resulting polymers obtained at the iterations exhibit sharp monomodal SEC distributions. The peak moves to the higher molecular weight side as the iteration proceeds. These polymers possessed observed molecular weights and degrees of benzyl bromide functionalization that agreed quite well the predictable values. All analyses of ${ }^{1} \mathrm{H}$ and ${ }^{13} \mathrm{C}$ NMR, IR, and elemental analysis $(\mathrm{Br} \%)$ confirmed the expected structures of these functionalized polymers. Thus, a series of five well-defined chainend-functionalized polystyrenes with two, four, eight, sixteen, and even thirty-two benzyl bromide moieties at the chain ends could be successfully synthesized. The tert-butyldimethylsilyloxymethylphenyl group thus introduced were always cleanly and quantitatively transformed into benzyl bromide moieties with $\left(\mathrm{CH}_{3}\right)_{3} \mathrm{SiCl}-$ $\mathrm{LiBr}$. In this transformation reaction, undesirable coupling among polymers often occurred in the reaction of methoxymethylphenyl group with $\mathrm{BCl}_{3}$ was not observed at all as mentioned before. At each stage in the iteration, the number of benzyl bromide moieties doubles. The benzyl bromide moieties are dendritically distributed at the chain ends as can be seen in Scheme 5. This method is especially effective for introducing a large number of benzyl bromide moieties.

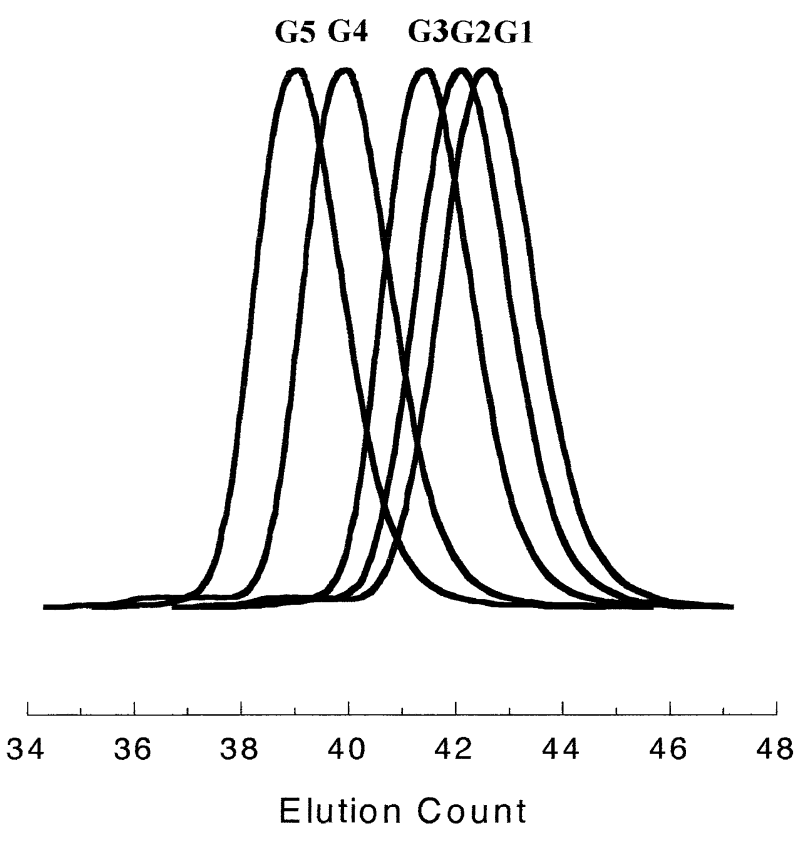

Figure 1. SEC chromatograms of chain-end-functionalized polystyrenes with two, four, eight, sixteen, and thirty-two benzyl bromide moieties (G1-G5).

In summary, various benzyl halide-functionalized polystyrenes have been synthesized by the methodologies based on the addition reaction of living anionic polymers to specially designed DPE derivatives substituted with methoxymethyl or tertbutyldimethylsilyloxymethyl groups in conjunction with transformation reaction into benzyl halide functions. A definite number of one to thirty-two benzyl chloride or bromide moieties was introduced at chain-ends or at the middle of chains. It is also possible to place benzyl halide moieties at any desired positions in chains. In addition to polystyrene, poly(styrene- $\left.d_{8}\right)$, poly $(\alpha$-methylstyrene), poly(4-methylstyrene), and their block copolymers were functionalized by the similar routes. More recently, we have successfully synthesized four-, six-, and eight-arm star polystyrenes with two benzyl bromide moieties at their cores, which will be described later. 
Coupling Reaction of Living Anionic Polymers with Benzyl Halide-Functionalized Polymers

In the early years of star polymer synthesis, multifunctional benzyl halide derivatives were often used as coupling agents in the reaction of living anionic polymers. Unfortunately, the coupling reactions were very complicated by serious side reactions such as metalhalogen exchange, benzyl proton abstraction, and single electron transfer reactions. As a result, considerable amounts of star polymers with lower and higher arms than desired were formed. ${ }^{105,106}$

Recently, Gauthier and Möller have reported that the side reactions can be virtually eliminated by end-capping polystyryllithium with DPE in the reaction of chloromethylated polystyrene with polystyryllithium. ${ }^{107,108}$ More recently, Hirao et al. ${ }^{109}$ and Hadjichristidis et al. ${ }^{110}$ have demonstrated that both poly(chloromethylstyrene)s and poly(bromomethylstyrene)s also couple quantitatively with polystyryllithium and polyisoprenyllithium endcapped with DPE in THF at $-40^{\circ} \mathrm{C}$ or under the similar conditions. Thus, these results strongly indicate a quantitative nature of the coupling reactions of this type under appropriate conditions. It is therefore expected that the benzyl halide functionalized polymers herein synthesized become effective coupling agents which can quantitatively react with living anionic polymers to synthesize star polymers.

In fact, we have successfully synthesized a variety of both regular and asymmetric star polymers by the coupling reactions of the benzyl halide-functionalized polymers with living anionic polymers of styrene, $\alpha$ methylstyrene, and isoprene that are end-capped with DPE. ${ }^{72,95,96,104}$ The regular stars have also be synthesized by using the same living polymers as polymeric coupling agents in main chain. The reactions were usually fast in THF even at $-78^{\circ} \mathrm{C}$ and went essentially to completion within $1 \mathrm{~h}$. However, the reactions were in most cases carried out for $24-168 \mathrm{~h}$ by way of precaution. A 1.2-fold or more excess of living anionic polymer was used to ensure complete coupling. The representative results are summarized in Table III. As expected, the coupling reactions of benzyl halide-functionalized polymers with DPE-endcapped living polymers were virtually quantitative under the conditions in THF at $-40 \sim-78^{\circ} \mathrm{C}$. On the other hand, undesirable star polymers with lower and higher arms $(\sim 10 \%)$ were formed in the coupling reactions with direct use of polystyryllithium or poly(isoprenyllithium). ${ }^{95}$

Asymmetric stars of the types $\mathrm{AA}_{n}^{\prime}$ and $\mathrm{AB}_{n}$ were actually synthesized by the coupling reaction of chainend-functionalized polymers with another living an-
Table III. Synthesis of asymmetric star polymers using benzyl halide-functionalized polystyrenes as polymeric coupling agents

\begin{tabular}{|c|c|c|c|c|c|c|}
\hline \multirow{2}{*}{ Type } & \multirow{2}{*}{ A } & \multirow{2}{*}{ B } & \multirow{2}{*}{$\mathrm{C}$} & \multicolumn{2}{|c|}{$M_{\mathrm{w}}\left(\mathrm{kg} \mathrm{mol}^{-1}\right)$} & \multirow{2}{*}{$\frac{M_{\mathrm{w}} / M_{\mathrm{n}}}{\mathrm{SEC}}$} \\
\hline & & & & $\overline{\text { Calcd }}$ & $\overline{\text { SLS }}$ & \\
\hline $\mathrm{AA}_{3}^{\prime}$ & $\mathrm{PS}^{\mathrm{a}}$ & & & 22.9 & 25.0 & 1.04 \\
\hline $\mathrm{AB}_{4}$ & PS & $\mathrm{PI}^{\mathrm{b}}$ & & 27.8 & 27.0 & 1.03 \\
\hline $\mathrm{AA}_{8}^{\prime}$ & PS & & & 44.0 & 44.7 & 1.03 \\
\hline $\mathrm{AB}_{8}$ & PS & PI & & 40.5 & 41.2 & 1.02 \\
\hline $\mathrm{AB}_{8}$ & PS & PS- $d_{8}{ }^{\mathrm{c}}$ & & 44.4 & 46.4 & 1.02 \\
\hline $\mathrm{AA}_{16}^{\prime}$ & PS & & & 88.1 & 87.6 & 1.05 \\
\hline $\mathrm{AA}_{32}^{\prime}$ & PS & & & 190 & 196 & 1.02 \\
\hline $\mathrm{A}_{2} \mathrm{~B}_{4}$ & PS & PI & & 28.4 & 30.5 & 1.05 \\
\hline $\mathrm{A}_{2} \mathrm{~B}_{8}$ & PS & PI & & 54.1 & 51.0 & 1.04 \\
\hline $\mathrm{A}_{2} \mathrm{~B}_{12}$ & PS & PI & & 88.4 & 83.2 & 1.04 \\
\hline $\mathrm{AA}^{\prime} \mathrm{A}_{2}^{\prime \prime}$ & PS & & & 21.0 & 23.1 & 1.05 \\
\hline $\mathrm{ABC}_{2}$ & PS & $\mathrm{P} \alpha \mathrm{MS}^{\mathrm{d}}$ & PI & 22.7 & 23.0 & 1.04 \\
\hline $\mathrm{ABC}_{4}$ & PS & $\mathrm{P} \alpha \mathrm{MS}$ & PI & 36.4 & 39.9 & 1.04 \\
\hline
\end{tabular}

ionic polymers. Both $\mathrm{A}_{2} \mathrm{~A}_{n}^{\prime}$ and $\mathrm{A}_{2} \mathrm{~B}_{n}$ star polymers were obtained when used in-chain-functionalized polymers whose benzyl halide moieties were placed at the middle of the chain. The synthesis of $\mathrm{AA}^{\prime} \mathrm{A}_{n}^{\prime \prime}$ and $\mathrm{AA}^{\prime} \mathrm{B}_{n}$ stars were possible by using in-chainfunctionalized polymers whose benzyl halide moieties were not located at the middle of the chain. Furthermore, asymmetric star polymers consisting of three different arms were synthesized by using in-chain-functionalized polystyrene-block-poly $(\alpha-$ methylstyrene) with two or four benzyl chloride moieties between two blocks in the coupling reaction with polyisoprenyllithium end-capped with DPE. Thus, $\mathrm{ABC}_{2}$ and $\mathrm{ABC}_{4}$ star polymers were obtained where $\mathrm{A}, \mathrm{B}$, and $\mathrm{C}$ were polystyrene, $\operatorname{poly}(\alpha$-methylstyrene), and polyisoprene segments, respectively. Star polymers carrying a large number of arms such as $\mathrm{AA}_{8}^{\prime}, \mathrm{AB}_{8}$, $\mathrm{A}_{2} \mathrm{~B}_{8}, \mathrm{~A}_{2} \mathrm{~B}_{12}, \mathrm{AA}_{16}^{\prime}$, and $\mathrm{AA}_{32}^{\prime}$ types were readily synthesized without any practical steric limitation.

Less reactive living anionic polymers of tert-butyl methacrylate and ethylene oxide could be coupled with benzyl halide-functionalized polymers to quantitatively afford asymmetric star polymers under appropriate conditions. ${ }^{98,111}$ In these coupling reactions, benzyl bromide functionality is more preferable than the chloride counterpart. The results are summarized in Table IV.

Thus, the proposed coupling reaction with use of benzyl halide-functionalized polymers offers a new general and versatile methodology for the synthesis of both regular and star polymers with well-defined architectures. The most advantageous feature of this methodology is that the functionalized polymers can intentionally and extensively designed and synthesized prior to the coupling reaction. Thus, the structure, es- 
Table IV. Synthesis of asymmetric star polymers by coupling reaction of benzyl bromide-functionalized polystyrenes with living anionic polymers of tert-butyl methacrylate and ethylene oxide

\begin{tabular}{lcccccc}
\hline \multirow{2}{*}{ Type } & \multirow{2}{*}{$\mathrm{A}$} & \multirow{2}{*}{$\mathrm{B}$} & $\mathrm{C}$ & \multicolumn{2}{c}{$M_{\mathrm{w}}\left(\mathrm{kg} \mathrm{mol}^{-1}\right)$} & \multicolumn{2}{c}{$M_{\mathrm{w}} / M_{\mathrm{n}}$} \\
\cline { 5 - 6 } & & & & Calcd & $\mathrm{SLS}$ & $\mathrm{SEC}$ \\
\hline $\mathrm{AB}_{2}$ & $\mathrm{PS}^{\mathrm{a}}$ & $\mathrm{P}^{t} \mathrm{BMA}^{\mathrm{b}}$ & & $14.9^{\mathrm{c}}$ & $14.3^{\mathrm{d}}$ & 1.05 \\
$\mathrm{AB}_{3}$ & $\mathrm{PS}$ & $\mathrm{P}^{t} \mathrm{BMA}$ & & 48.5 & 47.0 & 1.04 \\
$\mathrm{AB}_{4}$ & $\mathrm{PS}$ & $\mathrm{P}^{t} \mathrm{BMA}$ & & 72.7 & 74.0 & 1.05 \\
$\mathrm{ABC}_{4}$ & $\mathrm{PS}$ & $\mathrm{P} \alpha \mathrm{MS}$ & $\mathrm{P}^{t} \mathrm{BMA}$ & 33.2 & 33.4 & 1.03 \\
$\mathrm{AB}_{16}$ & $\mathrm{PS}$ & $\mathrm{PEO}^{\mathrm{f}}$ & & 99.0 & $99.0^{\mathrm{d}}$ & 1.02 \\
\hline
\end{tabular}

${ }^{\text {a Polystyrene. }}{ }^{\mathrm{b}}$ Poly(tert-butyl methacrylate). ${ }^{\mathrm{c}}$ Calculated

$M_{\mathrm{n}}$. ${ }^{\mathrm{d}}$ Determined by ${ }^{1} \mathrm{H}$ NMR. ${ }^{\text {ePoly }}(\alpha$-methylstyrene $)$.

${ }^{\text {f }}$ Poly(ethylene oxide).

pecially the number of arm, can be easily controlled in the star polymer synthesis. In particular, the use of such functionalized polymers is advantageous for the synthesis of asymmetric star polymers, since the structure of the stars can be widely synthesized by independently choosing functionalized polymers and living polymers to be reacted. Asymmetric as well as regular star polymers can be synthesized from the same functionalized polymeric coupling agent only by changing the living anionic polymers to be subsequently reacted. The possible use of a wide range of living anionic polymers in the coupling reaction is also advantageous for the synthesis of star polymers with chemical compositional variation.

\section{Coupling Reaction of Polymer Anions with Benzyl Halide-Functionalized Polymers}

In this section, we present a new development of the above-mentioned methodology, in which polymer anions consisting of two same or different polymer chains instead of living anionic polymers are used in the coupling reactions. ${ }^{97,98}$ The synthetic outline is illustrated in Scheme 6.

At first, a living anionic polymer is reacted with a chain-end-functionalized polymer with DPE moiety to prepare a polymer anion consisting of two polymer chains. In this reaction, three kinds of polymer anions of the type, $\mathrm{A}_{2}, \mathrm{AA}^{\prime}$, and $\mathrm{AB}$, can be obtained by changing the molecular weight and chemical composition of DPE-functionalized polymer or living anionic polymer. The resulting polymer anion is in-situ reacted with chain-end-functionalized polymer with two benzyl chloride moieties, thus forming a star polymer having five arms. Accordingly, two same or different polymer chains are simultaneously introduced at each of the two benzyl chloride moieties (also see in Scheme 6). With use of polymer anions consisting of different two chains, asymmetric star polymers of the types, $\mathrm{AA}_{2}^{\prime} \mathrm{A}_{2}^{\prime \prime}$ and $\mathrm{AB}_{2} \mathrm{C}_{2}$ can be obtained.

In order to investigate the usefulness of this method-

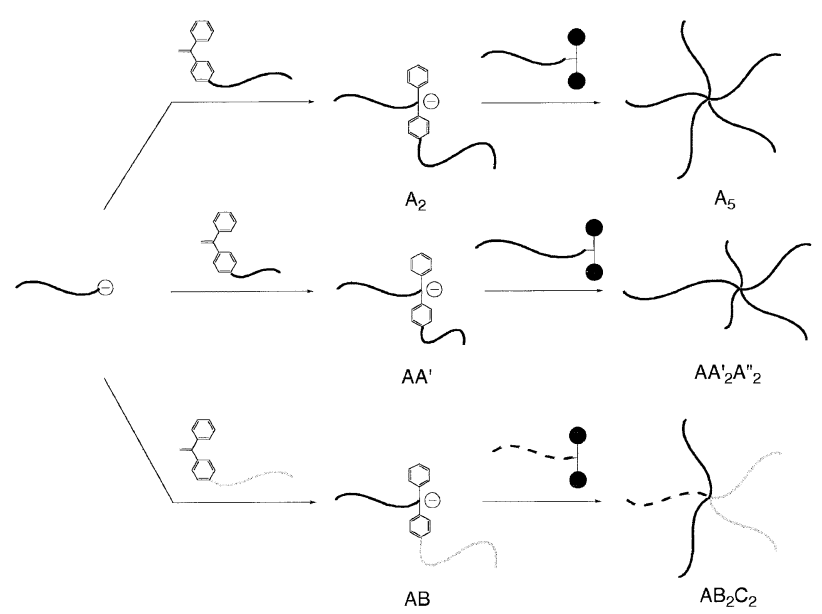

Scheme 6.

ology, the synthesis of an asymmetric five-arm $\mathrm{AA}_{2}^{\prime} \mathrm{A}_{2}^{\prime \prime}$ star polystyrene was first attempted. Polystyryllithium $\left(M_{\mathrm{n}}=3.1 \mathrm{~kg} \mathrm{~mol}^{-1}\right)$ was reacted with a 1.1 -fold excess of a DPE-chain-end-functionalized polystyrene $\left(M_{\mathrm{n}}=\right.$ $9.4 \mathrm{~kg} \mathrm{~mol}^{-1}$ ) to prepare a polymer anion consisting of two polystyrene chains with different molecular weights. The resulting polymer anion was then in-situ reacted with a chain-end-functionalized polystyrene with two benzyl chloride moieties $\left(M_{\mathrm{n}}=5.5 \mathrm{~kg} \mathrm{~mol}^{-1}\right)$. The reaction was fast and complete within $10 \mathrm{~min}$ under the conditions in THF at $-78^{\circ} \mathrm{C}$. This is rather surprising because the polymer anion appears to be more sterically hindered than the corresponding living polymer.

SEC profile of the reaction mixture is shown in Figure 2(A). There appears a main sharp monomodal peak along with two small peaks possibly for the unreacted or deactivated starting polystyryllithium, DPEchain-end-functionalized polystyrene, and polymer anion. The objective star polymer isolated by SEC fractionation was pure and free of its prepolymers as shown in Figure 2(B).

The results are summarized in Table V. The resulting star polymer possessed a predictable molecular weight with a narrow molecular weight distribution. The expected five-arm $\mathrm{AA}_{2}^{\prime} \mathrm{A}_{2}^{\prime \prime}$ asymmetric star polystyrene with well-defined architecture was thus obtained. Similarly, a five-arm $\mathrm{AB}_{2} \mathrm{C}_{2}$ star polymer was successfully synthesized by coupling the same functionalized polystyrene with a new polymer anion prepared from polyisoprenyllithium and a DPE-chain-endfunctionalized poly $(\alpha$-methylstyrene). The results are also listed in Table V.

The methodology using polymer anions can be extended to the synthesis of nine-arm $\mathrm{AA}_{4}^{\prime} \mathrm{A}_{4}^{\prime \prime}$ and $\mathrm{AB}_{4} \mathrm{C}_{4}$ asymmetric star polymers. ${ }^{73}$ The coupling reaction of a polymer anion consisting of two polystyrene chains with a chain-end-functionalized polystyrene with four 


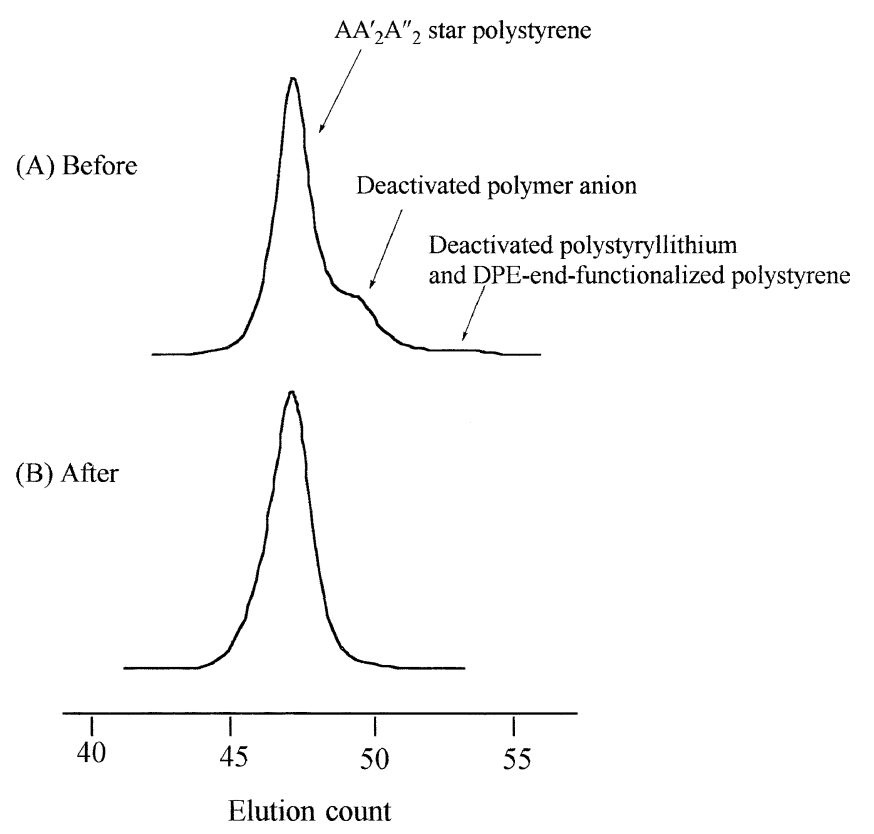

Figure 2. $\mathrm{SEC}$ chromatograms of $\mathrm{AA}_{2}^{\prime} \mathrm{A}_{2}^{\prime \prime}$ star polystyrenes before (A) and after (B) SEC fractionation.

Table V. Synthesis of asymmetric star polymers by coupling reaction of polymer anions with benzyl halide-functionalized polymers

\begin{tabular}{|c|c|c|c|}
\hline \multirow{2}{*}{ Type $^{\mathrm{a}}$} & \multicolumn{2}{|c|}{$M_{\mathrm{w}}\left(\mathrm{kg} \mathrm{mol}^{-1}\right)$} & \multirow{2}{*}{$\frac{M_{\mathrm{w}} / M_{\mathrm{n}}}{\mathrm{SEC}}$} \\
\hline & Calcd & SLS & \\
\hline $\mathrm{AA}_{2}^{\prime} \mathrm{A}_{2}^{\prime \prime}$ & 31.6 & 31.8 & 1.05 \\
\hline $\mathrm{AA}_{2}^{\prime} \mathrm{A}_{2}^{\prime \prime}$ & 83.3 & 90.9 & 1.04 \\
\hline $\mathrm{AB}_{2} \mathrm{C}_{2}$ & 27.5 & 27.5 & 1.10 \\
\hline $\mathrm{AA}_{4}^{\prime} \mathrm{A}_{4}^{\prime \prime}$ & 55.0 & 57.8 & 1.03 \\
\hline $\mathrm{AB}_{4} \mathrm{C}_{4}$ & 49.3 & 49.4 & 1.02 \\
\hline
\end{tabular}

${ }^{\mathrm{a}} \mathrm{A}, \mathrm{B}$, and $\mathrm{C}$ are polystyrene, polyisoprene, and $\operatorname{poly}(\alpha$-methylstyrene $)$, respectively.

benzyl chloride moieties efficiently proceeded to afford a nine-arm $\mathrm{AA}_{4}^{\prime} \mathrm{A}_{4}^{\prime \prime}$ asymmetric star polystyrene in a

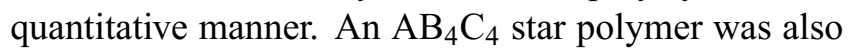
synthesized by the coupling reaction of the same benzyl chloride-functionalized polystyrene (A) with a polymer anion consisting of polyisoprene (B) and $\operatorname{poly}(\alpha-$ methylstyrene) (C) segments.

Thus, the coupling reaction with use of polymeric anion provides a new effective method that permits the synthesis of asymmetric star polymers with architectures characteristic of polymer anions. The key point of this methodology is that two same or different polymer chains can simultaneously be introduced by one reaction step. Furthermore, the structure of polymer anion can be advantageously designed by changing molecular weights and compositions of both the living anionic and DPE-functionalized polymers. Therefore, in addition to $\mathrm{AA}_{2}^{\prime} \mathrm{A}_{2}^{\prime \prime}$ and $\mathrm{AB}_{2} \mathrm{C}_{2}$ stars, different six other star polymers of the following types $\mathrm{A}_{5}, \mathrm{~A}_{3} \mathrm{~A}_{2}^{\prime}, \mathrm{AB}_{4}$,
$\mathrm{A}_{3} \mathrm{~B}_{2}, \mathrm{AA}_{2}^{\prime} \mathrm{B}_{2}$, and $\mathrm{AB}_{2} \mathrm{~B}_{2}^{\prime}$ can be in principle synthesized by the coupling reaction of a polymer anion and chain-end-functionalized polymer with two benzyl chloride moieties. As mentioned in section 1.1, a variety of benzyl halide-functionalized polymers are now available. Therefore, numerous combinations of such functionalized polymers with polymer anions may be possible in the coupling reaction. Another advantage is that the synthesis of asymmetric star polymers is always achieved in a one-pot reaction by the successive addition of DPE-functionalized polymer followed by benzyl chloride-functionalized polymer to living anionic polymer. It should be however considered that steric hindering effect among polymer anions and reaction sites of functionalized polymers becomes serious as the number of the benzyl halide moiety in a polymer chain increases.

\section{SYNTHESIS OF STAR POLYMERS BASED ON ITERATIVE APPROACH}

\section{Star Polymer Synthesis by Repeating Coupling and} Transformation Reactions

In the preceding chapter, we described a new methodology based on the coupling reaction of novel benzyl halide-functionalized polymers with either living anionic polymers or polymer anions consisting of two chains. A variety of regular and asymmetric star polymers were synthesized by changing benzyl halidefunctionalized polymers and living polymers. The coupling reaction is in itself a termination reaction and, as a matter of course, cannot be further continued.

Herein, we have proposed a new concept based on iterative approach, in which reaction sites can be always regenerated after the reaction and therefore further reactions can be repeated. With this iterative approach, star polymers may possibly be successively and, in principle, unlimitedly synthesized.

The first iterative approach applied to star polymer synthesis is shown in Scheme $7 .{ }^{112}$ Only two sets of reactions are needed for the entire iterative synthetic sequence: a coupling reaction and a transformation reaction. A starting polymer, in-chain-functionalized polystyrene with two benzyl bromide moieties, is prepared by the reaction of 1,4-dibromobutane with two equivalents of polystyryllithium end-capped with 1-(3-tert-butyldimethylsilyloxymethylphenyl)-1phenylethylene (5), followed by treatment with $\left(\mathrm{CH}_{3}\right)_{3} \mathrm{SiCl}-\mathrm{LiBr}$. At the first iteration, the inchain-functionalized polystyrene with two benzyl bromide moieties thus synthesized is reacted with two equivalents of polystyryllithium end-capped with $\mathbf{5}$ to afford a four-arm star polystyrene. Two tert- 


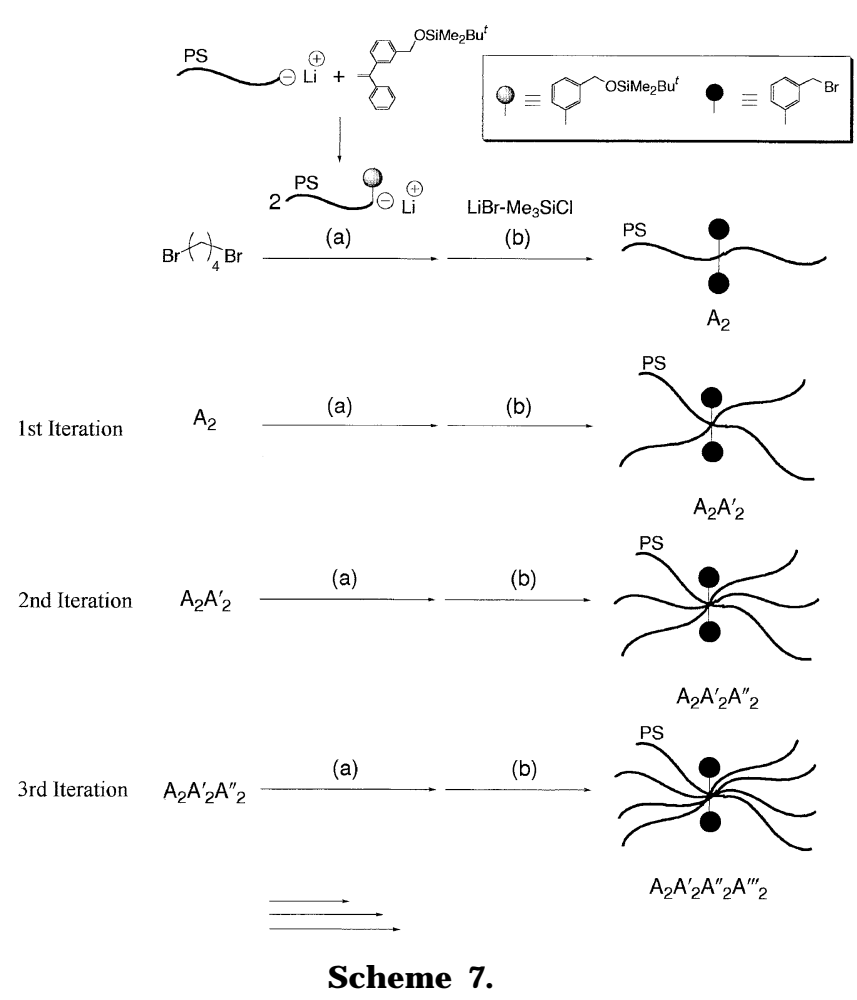

butyldimethylsilyloxymethylphenyl groups again introduced at the core of the star polymer are subsequently transformed into benzyl bromide groups with $\left(\mathrm{CH}_{3}\right)_{3} \mathrm{SiCl}-\mathrm{LiBr}$. At the second iteration, the resulting four-arm $\mathrm{A}_{2} \mathrm{~A}_{2}^{\prime}$ star polystyrene with two benzyl bromide moieties is employed as a starting material. The same two reactions, the coupling reaction with polystyryllithium end-capped with $\mathbf{5}$ and the transformation reaction with $\left(\mathrm{CH}_{3}\right)_{3} \mathrm{SiCl}-\mathrm{LiBr}$, are repeated. A six-arm $\mathrm{A}_{2} \mathrm{~A}_{2}^{\prime} \mathrm{A}_{2}^{\prime \prime}$ star polystyrene with two benzyl bromide moieties at the core can thus be obtained. If the two reactions in the iteration can further be continued, star polymers carrying eight, ten, or more arms will be successively synthesized.

In order to investigate the feasibility of the successive star polymer synthesis by this iterative methodology, the two reactions in the iteration were repeated three times for synthesizing four-, six-, and eight-arm star polystyrenes. As a matter of convenience for analyses, polystyryllithiums with similar molecular weights $\left(M_{\mathrm{n}}-10 \mathrm{~kg} \mathrm{~mol}^{-1}\right)$ were used in these syntheses. A 1.5fold excess of polystyryllithium was used in the coupling reaction to complete the reaction. The star polymers were always isolated in $c a .90 \%$ yield by the fractional precipitation. Figure 3 shows SEC profiles of the resulting polymers obtained by the first, second, and third iterations. As expected, these polymers exhibit sharp monomodal SEC distributions and move in turn to higher molecular weight sides. They possessed predictable molecular weights and narrow molecular weight distributions. The results are summarized in Ta-

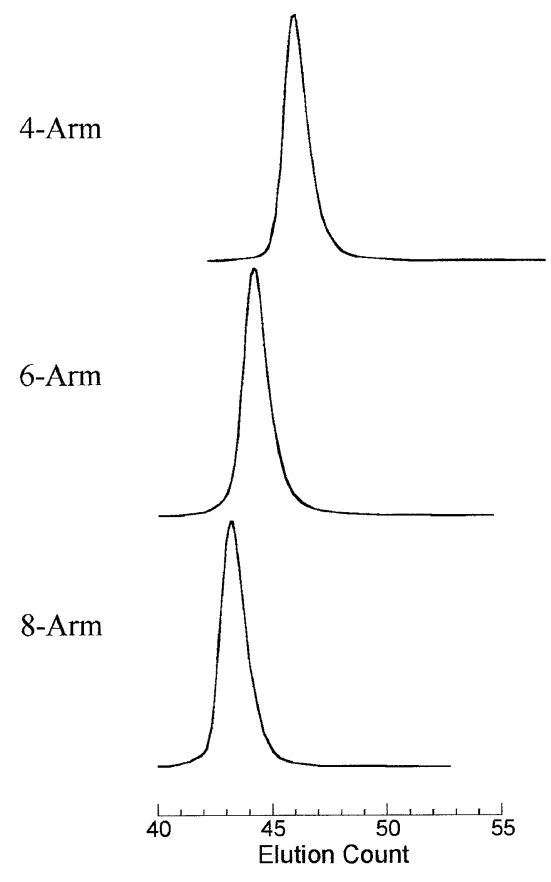

Figure 3. SEC chromatograms of the resulting star polystyrenes obtained by repeating coupling and transformation reactions three times.

Table VI. Synthesis of star polystyrenes by repeating coupling and transformation reactions

\begin{tabular}{ccccc}
\hline \multirow{2}{*}{ Type } & \multicolumn{3}{c}{$M_{\mathrm{w}}\left(\mathrm{kg} \mathrm{mol}^{-1}\right)$} & $M_{\mathrm{w}} / M_{\mathrm{n}}$ \\
\cline { 2 - 4 } \cline { 5 - 5 } & Calcd & SEC & SLS & SEC \\
\hline 2-Arm & 19.9 & 20.6 & 20.1 & 1.02 \\
4-Arm & 38.5 & 32.2 & 37.9 & 1.02 \\
6-Arm & 61.2 & 39.7 & 61.2 & 1.05 \\
8-Arm & 85.9 & 48.9 & 80.0 & 1.06 \\
\hline
\end{tabular}

ble VI.

The polymers thus synthesized can be regard as almost regular star polymers, since all of the arms consist of similar polystyrenes in molecular weight as mentioned before. The ratios of the intrinsic viscosities of star and linear polymers of equal molecular weight, $g^{\prime}=[\eta]_{\text {star }} /[\eta]_{\text {linear }}$, are given as a function of arm number $(f)$ and several reliable equations between $g^{\prime}$ and $f$ value based on the theoretical model and a semi-empirical theory have been proposed. ${ }^{113-118}$ Starbranched architecture with respect to arm number can be therefore demonstrated by the $g^{\prime}$ value. The experimental $g^{\prime}$ values were obtained by the ratios of intrinsic viscosities of the resulting stars measured in toluene at $35^{\circ} \mathrm{C}$ with those of the corresponding linear polymers obtained by the reported equation as shown below. ${ }^{119}$

$$
[\eta]=1.26 \times 10^{-4} M_{\mathrm{w}}^{0.71}
$$

The results are summarized in Table VII. The calculated $g^{\prime}$ values are also listed in this table. As can be seen, the overall experimental $g^{\prime}$ values are in good agreement with those calculated. This clearly indicates 
Table VII. Viscosities and $g^{\prime}$ values of 4-, 6-, and 8-arm star polystyrenes

\begin{tabular}{ccccccc}
\hline \multirow{2}{*}{ Type } & {$[\eta]_{\text {star }^{\mathrm{a}}}$} & & \multicolumn{2}{c}{$[\eta]_{\text {linear }}^{\mathrm{b}}$} & & \multicolumn{2}{c}{$g^{\prime}$} \\
\cline { 2 - 2 } \cline { 5 - 6 } \cline { 5 - 6 } & $\mathrm{dL} \mathrm{g}^{-1}$ & & $\mathrm{dL} \mathrm{g}^{-1}$ & & Exp. & Calcd $^{\mathrm{c}}$ \\
\hline 4-Arm & 0.168 & & 0.230 & & 0.73 & 0.71 \\
6-Arm & 0.187 & & 0.323 & & 0.58 & 0.56 \\
8-Arm & 0.189 & & 0.391 & & 0.48 & 0.46 \\
\hline
\end{tabular}

${ }^{\mathrm{a}}$ In toluene at $35^{\circ} \mathrm{C} .{ }^{\mathrm{b}} \mathrm{Calculated}$ from $[\eta]=1.26 \times 10^{-4} \mathrm{M}^{0.71}$. ${ }^{\mathrm{c}} g^{\prime}=\left[(3 f-2) / f^{2}\right]^{0.58} \times[0.724-0.015(f-1)] / 0.724 .^{117}$

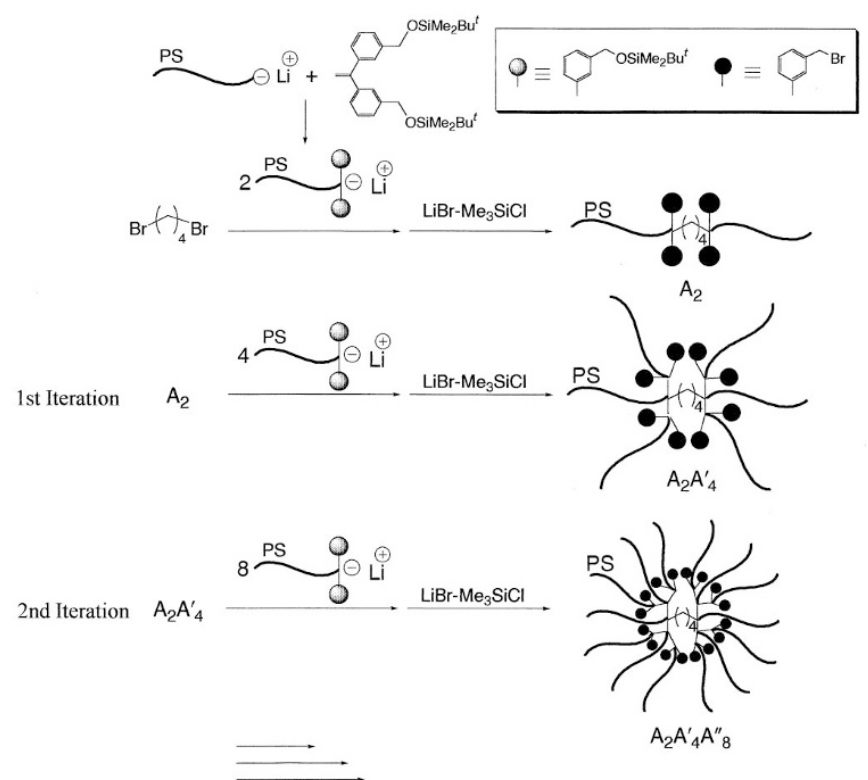

Scheme 8.

the expected star-branched architectures of the stars synthesized by this iterative methodology.

Well-defined four-, six-, and eight-arm star polystyrenes were thus successively synthesized by repeating the iteration three times. At each stage in the iteration, the number of arm increases to double. Since the eight-arm star possesses two benzyl bromide moieties at the core, the iterative reaction sequence can further be continued. A series of asymmetric star polymers of the type $A_{2} B_{2}, A_{2} B_{2} C_{2}$, and so on may possibly be synthesized simply by changing living anionic polymers to be reacted in each iteration. If a living polymer end-capped with $\mathbf{4}$ is used in the coupling reaction, star polymers with a large number of arms will readily be obtained as illustrated in Scheme 8.

Star polymers obtained by this methodology possess two benzyl bromide moieties at the cores and therefore can also be utilized as polymeric coupling agents in the methodology described before. Especially, the combination of such benzyl bromide-functionalized stars with polymer anions may permit the synthesis of asymmetric star polymers with more complex architectures that are difficult to be synthesized by any other methods.
Star Polymer Synthesis by Repeating Living Linking Reaction and Introduction of DPE Moieties

In the preceding section, we demonstrated the feasibility of successive star polymer synthesis based on an iterative approach. Well-defined, four-, six-, and eight-arm star polymers were successively synthesized by repeating the iterative reaction sequence three times. Herein, we have developed an alternative iterative methodology. ${ }^{120}$ As illustrated in Scheme 9, the methodology also requires only two sets of the reactions at each stage in the iteration: a living linking reaction of DPE derivatives or DPE-functionalized polymers with living anionic polymers and an in-situ reaction of 1-[4-(4-bromobutyl)phenyl]-1-phenylethylene (6) with the 1,1-diphenylalkyl anions generated by the linking reaction to introduce two DPE moieties. Advantageously, the two reaction steps can be carried out in a one-pot by successively adding living polymer followed by 6 to DPE derivatives or DPE-functionalized polymers. There is no need for the isolation of the intermediate polymer in each reaction step.

At the first iteration, the living linking reaction of two equivalents of living anionic polymer with 1,3-bis(1phenylethenyl)benzene was carried out to afford a living linked product having two 1,1-diphenylalkyl anions newly generated at the junction point between two polymer chains. These two anions were in-situ reacted with 6 for introducing two DPE moieties exactly at the middle of the polymer chain. At the second stage in the iteration, the living linking reaction was again carried out between two equivalents of another living polymer and the resulting in-chain-functionalized polymer with two DPE moieties, followed by in-situ treatment with 6. As a result, a four-arm star polymer having two DPE moieties at the core was obtained. Similarly, a six arm star polymer having two DPE moieties could be synthesized by repeating the same two reactions on the four-arm star polymer obtained at the third stage of the iteration.

In each living linking reaction, a 1.2-fold excess of living anionic polymer relative to DPE moiety was always used to go essentially to completion. The objective star polymers were always isolated in $c a$. $90 \%$ yields by SEC fractionation. The two reactions in each of the iterations were very fast and complete within $10 \mathrm{~min}$ in $\mathrm{THF}$ at $-78^{\circ} \mathrm{C}$ even in the third iteration except for the first linking reaction of polystyryllithium with 1,3-bis(1-phenylethenyl)benzene. This linking reaction was carried out in tert-butylbenzene at room temperature for $1 \mathrm{~h}$, since Quirk and his coworkers previously reported that the same linking reaction was a very efficient reaction in hydrocarbon solvents. Indeed, the reaction quantitatively proceeded in tert- 


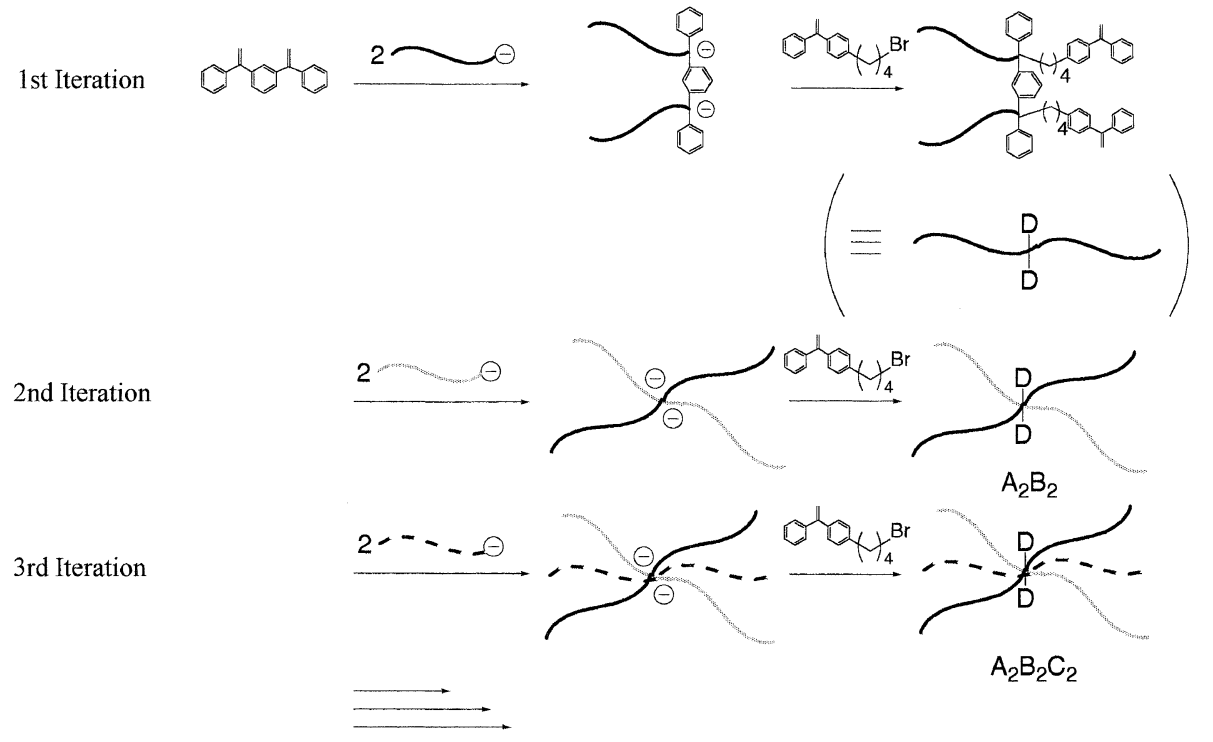

Scheme 9.

Table VIII. Synthesis of star polymers by repeating living linking reactions and introduction of DPE moieties

\begin{tabular}{|c|c|c|c|c|}
\hline \multirow{2}{*}{ Type $^{\mathrm{a}}$} & \multicolumn{2}{|c|}{$M_{\mathrm{n}}\left(\mathrm{kg} \mathrm{mol}^{-1}\right)$} & \multirow{2}{*}{$\frac{M_{\mathrm{w}}\left(\mathrm{kg} \mathrm{mol}^{-1}\right)}{\mathrm{SLS}}$} & \multirow{2}{*}{$\frac{M_{\mathrm{w}} / M_{\mathrm{n}}}{\mathrm{SEC}}$} \\
\hline & $\overline{\text { Calcd }}$ & VPO & & \\
\hline $\mathrm{A}_{2}$ & 21.2 & $22.1^{\mathrm{b}}$ & 22.3 & 1.01 \\
\hline $\mathrm{A}_{2} \mathrm{~A}_{2}^{\prime}$ & 42.1 & 42.1 & 41.4 & 1.02 \\
\hline $\mathrm{A}_{2} \mathrm{~A}_{2}^{\prime} \mathrm{A}_{2}^{\prime \prime}$ & 62.2 & 60.3 & 64.4 & 1.04 \\
\hline $\mathrm{A}_{2} \mathrm{~B}_{2}$ & 41.5 & 41.7 & 41.8 & 1.02 \\
\hline $\mathrm{A}_{2} \mathrm{~B}_{2} \mathrm{C}_{2}$ & 60.3 & 60.4 & 62.4 & 1.02 \\
\hline
\end{tabular}

${ }^{\mathrm{a}} \mathrm{A}, \mathrm{B}$, and $\mathrm{C}$ are polystyrene, poly $(\alpha$-methylstyrene), and poly(4-methoxystyrene), respectively. ${ }^{b}$ Determined by SEC.

butylbenzene, while it was slow and incomplete in THF at $-78^{\circ} \mathrm{C}$ for $24 \mathrm{~h} .{ }^{49,51}$

With this methodology, $\mathrm{A}_{2}, \mathrm{~A}_{2} \mathrm{~A}_{2}^{\prime}, \mathrm{A}_{2} \mathrm{~A}_{2}^{\prime} \mathrm{A}_{2}^{\prime \prime}$, and $\mathrm{A}_{2} \mathrm{~B}_{2}, \mathrm{~A}_{2} \mathrm{~B}_{2} \mathrm{C}_{2}$ asymmetric star polymers were successively synthesized. In each of these stars, A, B, $\mathrm{C}$ segments were polystyrene, poly(4-methoxystyrene), $\operatorname{poly}(\alpha$-methylstyrene), or polyisoprene. The results are summarized in Table VIII. As can be seen, the resulting star polymers all possess predictable molecular weights and narrow molecular weight distributions as well as the expected compositions. Thus, the two reactions in each iterative sequence can be repeated three times without problem. As the resulting six-arm star polymers have two DPE moieties at the cores, the further iteration may possibly be repeated. In addition to the stars of the type $\mathrm{A}_{2} \mathrm{~A}_{2}^{\prime} \mathrm{A}_{2}^{\prime \prime}$ and $\mathrm{A}_{2} \mathrm{~B}_{2} \mathrm{C}_{2}$ herein synthesized, it is possible to synthesize $\mathrm{A}_{6}, \mathrm{~A}_{4} \mathrm{~A}_{2}^{\prime}, \mathrm{A}_{4} \mathrm{~B}_{2}$, $\mathrm{A}_{2} \mathrm{~A}_{2}^{\prime} \mathrm{B}_{2}, \mathrm{~A}_{2} \mathrm{~B}_{4}$, and $\mathrm{A}_{2} \mathrm{~B}_{2} \mathrm{~B}_{2}^{\prime}$ star polymers at the third stage of the iteration.

The methodology can be extended to the synthesis of more complex star polymers by using 1,1-bis[3-(1phenylethenyl)phenyl]ethylene consisting of three DPE moieties as a first core compound as illustrated in Scheme $10 .{ }^{121}$ The reaction sequence at each stage of

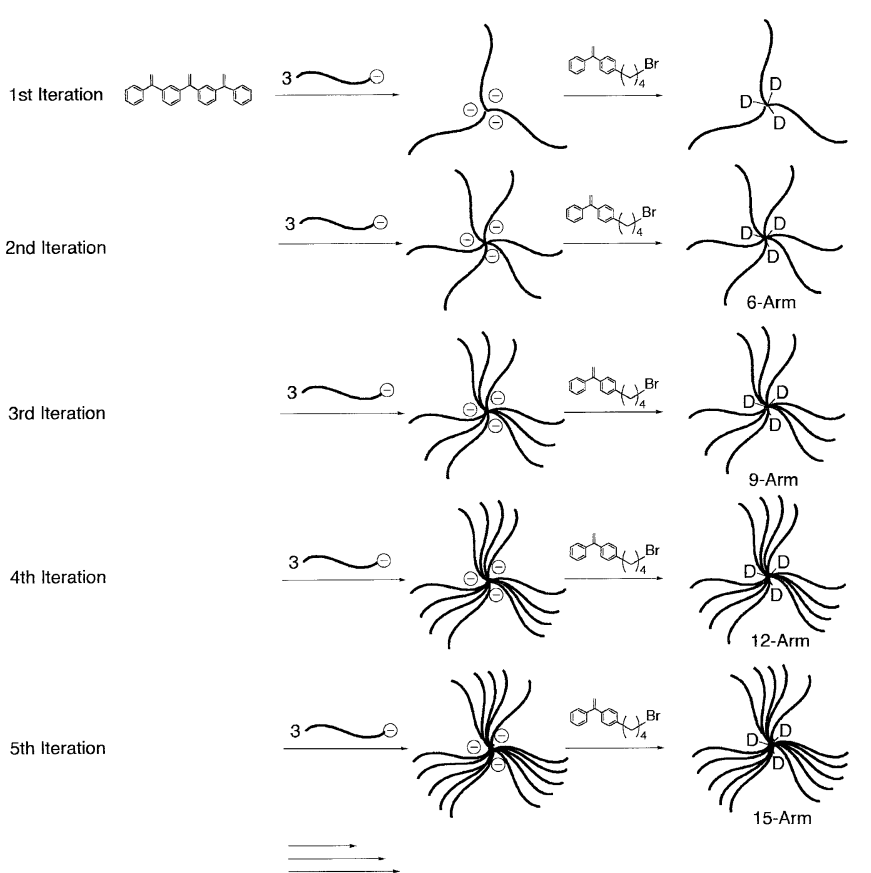

Scheme 10.

the iterations is very similar to that used in the abovementioned methodology (see Scheme 9). The synthesis of a series of star polymers of the types $\left(\mathrm{A}_{3}\right)_{n}$, $\left(\mathrm{A}_{3} \mathrm{~A}_{3}^{\prime} \mathrm{A}_{3}^{\prime \prime} \ldots\right),\left(\mathrm{A}_{3} \mathrm{~B}_{3} \mathrm{C}_{3} \ldots\right)$, and their mixed structures are expected.

The two reactions in the iteration were repeated five times using polystyryllithiums having similar molecular weights $\left(M_{\mathrm{n}}-10 \mathrm{~kg} \mathrm{~mol}^{-1}\right)$ (see also Scheme 10$)$. These reactions were always fast and went essentially to completion within $10 \mathrm{~min}$ in THF at $-78^{\circ} \mathrm{C}$ except for the first linking reaction of 1,1-bis[3-(1phenylethenyl)phenyl]ethylene with polystyryllithium that was performed in tert-butylbenzene at $25^{\circ} \mathrm{C}$ for $1 \mathrm{~h}$. The polymer yield was always quantitative in each case. 
Table IX. Synthesis of star polystyrenes by repeating living linking reactions and introduction of DPE moieties

\begin{tabular}{cccccc}
\hline \multirow{2}{*}{ Type $^{\mathrm{a}}$} & \multicolumn{3}{c}{$M_{\mathrm{w}}\left(\mathrm{kg} \mathrm{mol}^{-1}\right)$} & & $M_{\mathrm{w}} / M_{\mathrm{n}}$ \\
\cline { 2 - 4 } & Calcd & SEC & SLS & & SEC \\
\hline 3-Arm & 33.6 & 28.1 & 32.2 & & 1.02 \\
6-Arm & 68.9 & 45.1 & 69.7 & & 1.03 \\
9-Arm & 103 & 65.7 & 102 & \\
12-Arm & 141 & 77.9 & 142 & & 1.04 \\
15-Arm & 173 & 85.6 & 175 & & 1.04 \\
\hline
\end{tabular}

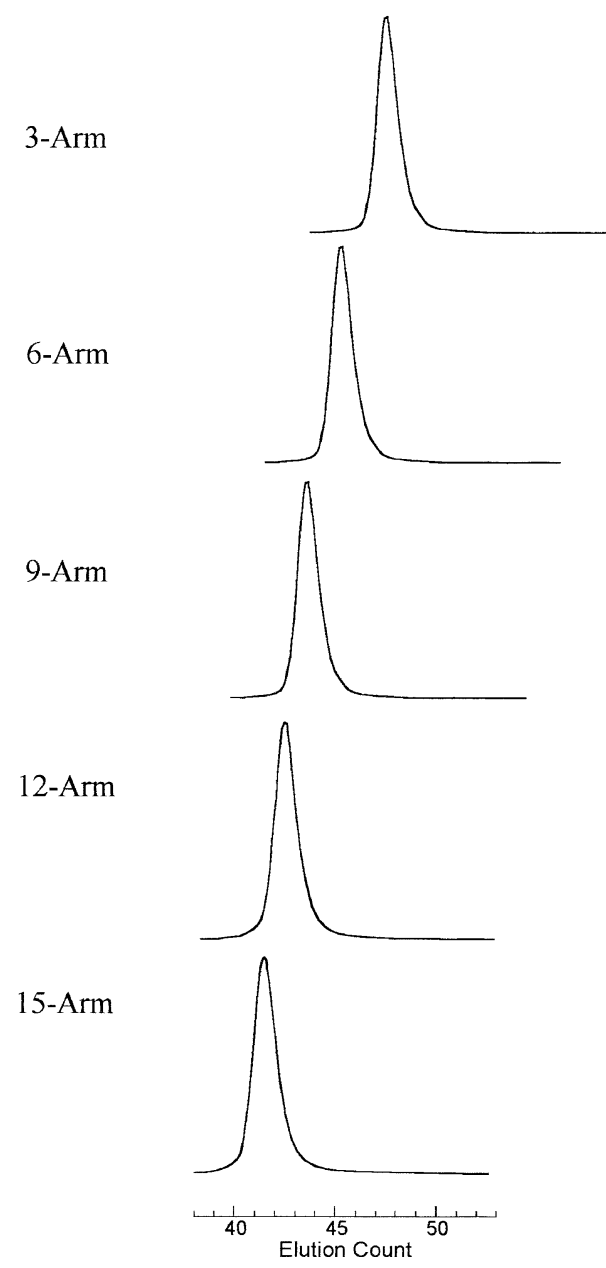

Figure 4. SEC chromatograms of the resulting star polystyrenes obtained by repeating living linking and in-situ reactions five times.

The results are summarized in Table IX.

As shown in Figure 4, the resulting polymers all exhibit sharp monomodal SEC distributions without any shoulders and tailings. The observed molecular weights agreed quite well with those predicted and narrow molecular weight distributions were attained in all samples. Excellent agreement between $g^{\prime}$ values observed and calculated was observed in each sample as was seen in Table X. Accordingly, the two reactions in the iteration could be repeated five times to afford a series of the expected three-, six-, nine-, twelve-, and fifteen-arm star polystyrenes with well-defined architectures. Very surprisingly, steric limitation was not
Table X. Viscosities and $g^{\prime}$ values of 3-, 6-, 9-, 12-, and 15-arm star polystyrenes

\begin{tabular}{ccccccc}
\hline \multirow{2}{*}{ Type } & {$[\eta]_{\text {star }^{\mathrm{a}}}{ }^{\mathrm{a}}$} & & {$[\eta]_{\text {linear }} \mathrm{b}^{\mathrm{b}}$} & & \multicolumn{2}{c}{$g^{\prime}$} \\
\cline { 2 - 2 } \cline { 5 - 6 } \cline { 5 - 6 } & $\mathrm{dL} \mathrm{g}^{-1}$ & & $\mathrm{dL} \mathrm{g}^{-1}$ & & Exp. & Calcd $^{\mathrm{b}}$ \\
\hline 3-Arm & 0.174 & & 0.205 & & 0.85 & 0.83 \\
6-Arm & 0.194 & & 0.354 & & 0.55 & 0.56 \\
9-Arm & 0.198 & & 0.464 & & 0.43 & 0.42 \\
12-Arm & 0.201 & & 0.587 & & 0.34 & 0.33 \\
15-Arm & 0.199 & & 0.681 & & 0.29 & 0.27 \\
\hline
\end{tabular}

${ }^{\mathrm{a}}$ In toluene at $35^{\circ} \mathrm{C} .{ }^{\mathrm{b}} \mathrm{Calculated}$ from $[\eta]=1.26 \times 10^{-4} \mathrm{M}^{0.71}$. ${ }^{\mathrm{c}} g^{\prime}=\left[(3 f-2) / f^{2}\right]^{0.58} \times[0.724-0.015(f-1)] / 0.724 .^{117}$

practically encountered even at the fifth iteration under the conditions employed.

Similarly, well-defined $\mathrm{A}_{3} \mathrm{~B}_{3}$, and $\mathrm{A}_{3} \mathrm{~B}_{3} \mathrm{C}_{3}$ asymmetric star polymers were also successively synthesized starting from the same $\mathrm{A}_{3}$ star polystyrene. The results are summarized in Table XI. In the $\mathrm{A}_{3} \mathrm{~B}_{3} \mathrm{C}_{3}$ asymmetric stars, their $\mathrm{A}, \mathrm{B}$, and $\mathrm{C}$ segments were polystyrene, poly(4-methoxystyrene), poly(4tert-butyldimethylsilyloxystyrene), and polystyrene, poly(4-methoxystyrene), poly(4-trimethylsilylstyrene), and polystyrene, poly(4-methoxystyrene), polyisoprene, respectively.

The reliability and usefulness as well as the generality and potential versatility of the proposed iterative methodologies are thus demonstrated by these successful results. Since the reaction sites are always regenerated after each of the iterations, star polymers can be successively and, in principle, unlimitedly synthesized until serious steric limitation is encountered. The future success of this methodology is strongly dependent on how many times the iterative reaction sequences can be repeated. The star polymers obtained at each stage of the iterations are used as starting materials in the next iteration. Accordingly, a series of star polymers with same or different arms can be systematically synthesized by changing living anionic polymers in the linking reactions. The methodology can be further extend to the synthesis of a wide variety of star polymers of the types $\left(\mathrm{A}_{x}\right)_{n},\left(\mathrm{~A}_{x} \mathrm{~B}_{x} \mathrm{C}_{x} \ldots\right),\left(\mathrm{A}_{x} \mathrm{~A}_{x}^{\prime} \mathrm{A}_{x}^{\prime \prime} \ldots\right)$, and the mixed architectures by using DPE derivatives consisting of $x$ DPE moieties as starting core compounds. The intermediate star polymers having two anions will be able to behave as star polymeric initiators to polymerize additional monomers, thus forming star polymers of different type. Any monomer, which undergoes living anionic polymerization, can be used in the further polymerization. 
Table XI. Synthesis of asymmetric star polymers by repeating living linking reactions and introduction of DPE moieties

\begin{tabular}{|c|c|c|c|c|c|c|c|}
\hline \multirow{2}{*}{ Type } & \multirow{2}{*}{ A } & \multirow{2}{*}{ B } & \multirow{2}{*}{$\mathrm{C}$} & \multicolumn{2}{|c|}{$M_{\mathrm{n}}\left(\mathrm{kg} \mathrm{mol}^{-1}\right)$} & \multirow{2}{*}{$\frac{M_{\mathrm{w}}\left(\mathrm{kg} \mathrm{mol}^{-1}\right)}{\mathrm{SLS}}$} & \multirow{2}{*}{$\frac{M_{\mathrm{w}} / M_{\mathrm{n}}}{\mathrm{SEC}}$} \\
\hline & & & & $\overline{\text { Calcd }}$ & VPO & & \\
\hline $\mathrm{A}_{3} \mathrm{~B}_{3}$ & $\mathrm{PS}^{\mathrm{a}}$ & $\mathrm{PMOS}^{\mathrm{b}}$ & & 65.8 & 64.2 & 66.7 & 1.03 \\
\hline $\mathrm{A}_{3} \mathrm{~B}_{3} \mathrm{C}_{3}$ & PS & PMOS & $\operatorname{PSOS}^{\mathrm{c}}$ & 95.1 & 94.4 & 97.1 & 1.02 \\
\hline $\mathrm{A}_{3} \mathrm{~B}_{3} \mathrm{C}_{3}$ & PS & PMOS & $\operatorname{PSS}^{\mathrm{d}}$ & 95.4 & 93.9 & 97.2 & 1.03 \\
\hline $\mathrm{A}_{3} \mathrm{~B}_{3} \mathrm{C}_{3}$ & PS & PMOS & $\mathrm{PI}^{\mathrm{e}}$ & 96.7 & 96.6 & 103 & 1.04 \\
\hline
\end{tabular}

${ }^{\mathrm{a}}$ Polystyrene. ${ }^{\mathrm{b}}$ Poly(4-methoxystyrene). ${ }^{\mathrm{c}}$ Poly(4-tert-butyldimethylsilyloxystyrene). ${ }^{\mathrm{d}}$ Poly(4-trimethylsilylstyrene). ${ }^{\mathrm{e}}$ Polyisoprene.
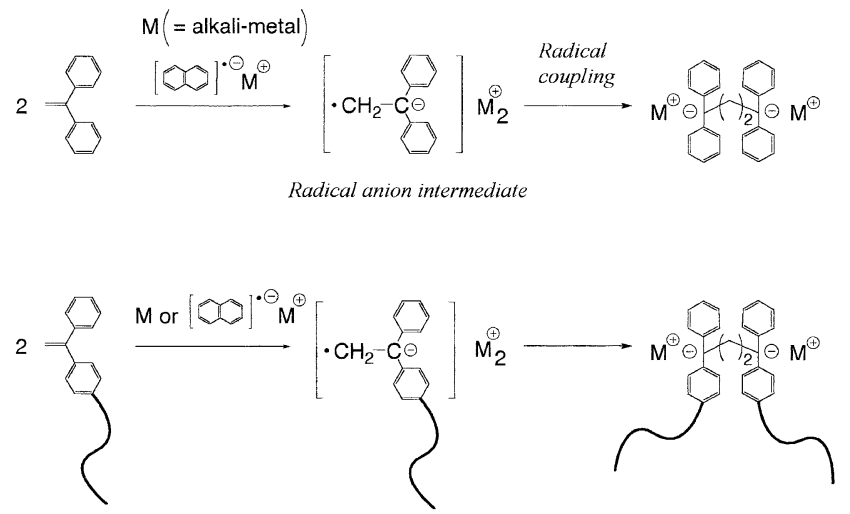

Scheme 11.

Synthesis of Star Polymers by Means of Radical Coupling Reaction of DPE-Functionalized Polymers with Potassium Naphthalenide

In the iterative methodology mentioned before, the living linked product with two anions is one of the key starting materials for the successive synthesis of star polymers. We have recently synthesized structurally similar in-chain functionalized polymers with two anions by the radical coupling reaction of chain-endfunctionalized polymers with DPE moiety with alkalimetal naphthalenides. ${ }^{122}$ Similar to the radical coupling reaction of DPE and its derivatives, an in-chainfunctionalized polymer with two anions was formed possibly via the formation of radical anion intermediate followed by radical coupling between the intermediates as illustrated in Scheme 11.

The radical coupling reaction of DPE-chain-endfunctionalized polymers was carried out in THF at $-78^{\circ} \mathrm{C}$ with a 1.5 -fold excess of potassium naphthalenide. The results are summarized in Table XII. The reaction proceeded very fast and finished within $10 \mathrm{~min}$. The chain-end-functionalized polystyrene with a $M_{\mathrm{n}}$ value of $5.69 \mathrm{~kg} \mathrm{~mol}^{-1}$ was coupled in $96 \%$ yield under the conditions. In the $M_{\mathrm{n}}$ range of 1.86 $9.47 \mathrm{~kg} \mathrm{~mol}^{-1}$, the yields always exceeded over $90 \%$. However, the yield gradually decreased with increasing molecular weight and fell in 59\% when used a polymer of a $M_{\mathrm{n}}$ of $33.9 \mathrm{~kg} \mathrm{~mol}^{-1}$ in the reaction. Thus, the molecular weight of DPE-functionalized polystyrene
Table XII. Radical coupling reaction of DPE-chain-end-functionalized polymers with potassium naphthalenide in THF at $-78^{\circ} \mathrm{C}$ for $1 \mathrm{~h}$

\begin{tabular}{ccc}
\hline \multicolumn{2}{c}{ DPE-chain-end-functionalized polystyrene } & Dimer yield (\%) \\
\hline Type & $M_{\mathrm{n}}\left(\mathrm{kg} \mathrm{mol}^{-1}\right)^{\mathrm{a}}$ & 98 \\
\hline PS $^{\mathrm{b}}$ & 1.86 & 96 \\
PS & 5.69 & 92 \\
PS & 6.12 & 91 \\
PS & 9.47 & 84 \\
PS & 15.8 & 68 \\
PS & 23.4 & 59 \\
PS & 33.9 & 95 \\
PI & 4.95 & 91 \\
PI & 10.4 & 60 \\
PI & 20.8 & 91 \\
P $\alpha$ MS $^{\text {d }}$ & 4.47 & \\
\hline
\end{tabular}

${ }^{\mathrm{a}}$ Determined by SEC. ${ }^{\mathrm{b}}$ Polystyrene. ${ }^{\mathrm{c}}$ Polyisoprene. ${ }^{\mathrm{d}} \mathrm{Poly}(\alpha-$ methylstyrene).

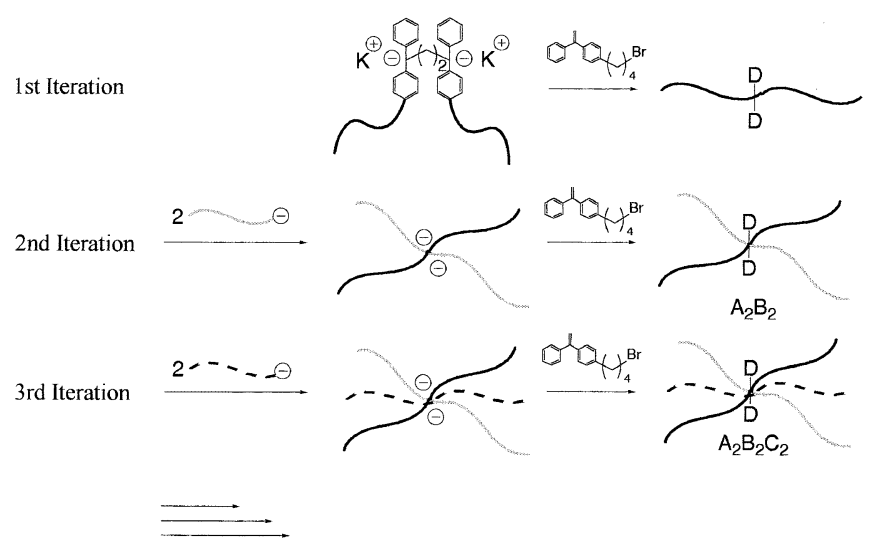

Scheme 12.

affected significantly the yield of coupling product. Both DPE-chain-end-functionalized polyisoprene and $\operatorname{poly}(\alpha$-methylstyrene) also underwent radical coupling reaction under the same conditions. High yields more than $90 \%$ were achieved with use of polymers of $M_{\mathrm{n}}$ values of $4.47-10.4 \mathrm{~kg} \mathrm{~mol}^{-1}$. No difference in the yield was observed by the difference of the main chain among these polymers.

As illustrated in Scheme 12, the iterative reaction sequence was carried out with use of the coupled product with two anions, similar to Scheme 9. Two DPE moieties were introduced into the coupled prod- 
Table XIII. Synthesis of star polymers by the iterative approach using dimeric coupled product with two 1,1-diphenylalkyl anions

\begin{tabular}{|c|c|c|c|c|c|c|}
\hline \multirow{2}{*}{ Type } & \multirow{2}{*}{ A } & \multirow{2}{*}{ B } & \multirow{2}{*}{$\mathrm{C}$} & \multicolumn{2}{|c|}{$M_{\mathrm{w}}\left(\mathrm{kg} \mathrm{mol}^{-1}\right)$} & \multirow{2}{*}{$\frac{M_{\mathrm{w}} / M_{\mathrm{n}}}{\mathrm{SEC}}$} \\
\hline & & & & Calcd & $\overline{\text { SLS }}$ & \\
\hline $\mathrm{A}_{2}$ & $\mathrm{PS}^{\mathrm{a}}$ & & & $12.7^{\mathrm{b}}$ & $11.7^{\mathrm{c}}$ & 1.01 \\
\hline $\mathrm{A}_{2} \mathrm{~A}_{2}^{\prime}$ & PS & & & 23.3 & 23.4 & 1.03 \\
\hline $\mathrm{A}_{2} \mathrm{~A}_{2}^{\prime} \mathrm{A}_{2}^{\prime \prime}$ & PS & & & 33.1 & 33.9 & 1.05 \\
\hline $\mathrm{A}_{2}$ & $\mathrm{PI}^{\mathrm{d})}$ & & & $10.4^{\mathrm{b}}$ & $11.0^{\mathrm{c}}$ & 1.02 \\
\hline $\mathrm{A}_{2} \mathrm{~B}_{2}$ & PI & $\mathrm{P}(\alpha \mathrm{MS})^{\mathrm{e}}$ & & 20.8 & 21.0 & 1.02 \\
\hline $\mathrm{A}_{2} \mathrm{~B}_{2} \mathrm{C}_{2}$ & PI & $\mathrm{P}(\alpha \mathrm{MS})$ & PS & 34.8 & 31.8 & 1.06 \\
\hline
\end{tabular}

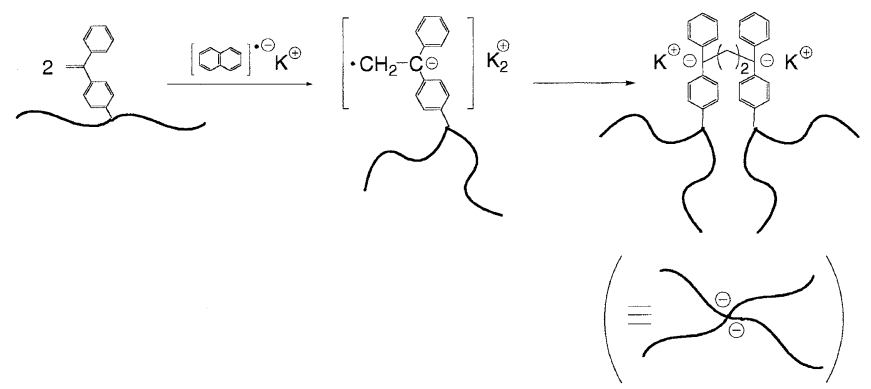

Scheme 13.

uct via the two anions by treatment with $\mathbf{6}$. The second and third iterations were the same as those described before. Asymmetric star polymers of $\mathrm{A}_{2} \mathrm{~A}_{2}^{\prime}$, $\mathrm{A}_{2} \mathrm{~A}_{2}^{\prime} \mathrm{A}_{2}^{\prime \prime}$ and $\mathrm{A}_{2} \mathrm{~B}_{2}, \mathrm{~A}_{2} \mathrm{~B}_{2} \mathrm{C}_{2}$ were successfully synthesized (see Table XIII). Thus, the coupled products obtained by the radical coupling reaction of DPE-chainend-functionalized polymers could be used as starting materials for iterative star polymer synthesis.

In the next attempt, the radical coupling reaction was applied to in-chain-functionalized polymer with DPE moiety. If the DPE-in-chain-functionalized polymer undergoes radical coupling reaction, a four-arm star polymer will be formed as illustrated in Scheme 13. The resulting star polymer may have two anions at the core, the structure of which is almost same as the intermediate star polymer obtained at the second iteration mentioned above (see Scheme 9).

In-chain-functionalized polymers with DPE moiety can readily be obtained by the reaction of DPE-chainend-functionalized polymers with slight excess of living anionic polymers followed by in-situ treatment with 6 as illustrated in Scheme 14. Since the starting DPEfunctionalized polymers and living anionic polymers were designed to be very similar in molecular weight, the DPE moiety thus introduced was placed nearly at the middle of the chain in each polymer sample. Two DPE-in-chain-functionalized polystyrenes with different molecular weights and one DPE-in-chainfunctionalized polyisoprene were synthesized. In ad-

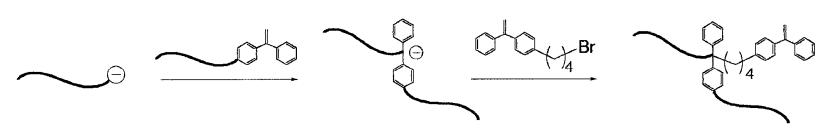

Scheme 14.

Table XIV. Synthesis of DPE-in-chain-functionalized

\begin{tabular}{|c|c|c|c|c|c|}
\hline \multirow{2}{*}{ Type $^{\mathrm{a}}$} & \multicolumn{2}{|c|}{$M_{\mathrm{n}}\left(\mathrm{kg} \mathrm{mol}^{-1}\right)$} & \multirow{2}{*}{$\frac{M_{\mathrm{w}} / M_{\mathrm{n}}}{\mathrm{SEC}}$} & \multicolumn{2}{|c|}{ DPE-functionality } \\
\hline & $\overline{\text { Calcd }}$ & $\overline{\text { SEC }}$ & & Calcd & ${ }^{1} \mathrm{H}$ NMR \\
\hline $\mathrm{AA}^{\prime}$ & 9.56 & 9.33 & 1.01 & 1 & $1.0_{0}$ \\
\hline $\mathrm{AA}^{\prime}$ & 19.4 & 19.6 & 1.06 & 1 & $1.0_{2}$ \\
\hline $\mathrm{BB}^{\prime}$ & 20.1 & 21.7 & 1.03 & 1 & $1.0_{5}$ \\
\hline $\mathrm{AB}$ & 20.0 & $21.3^{\mathrm{b}}$ & 1.04 & 1 & $1.0_{3}$ \\
\hline
\end{tabular}

${ }^{\mathrm{a}} \mathrm{A}$ and $\mathrm{B}$ are polystyrene and polyisoprene, respectively.

${ }^{\mathrm{b}}$ Determined by ${ }^{1} \mathrm{H}$ NMR.

dition, a new in-chain-functionalized block copolymer with DPE moiety between two blocks, polystyreneblock-polyisoprene, was synthesized by the reaction of a DPE-chain-end-functionalized polyisoprene with polystyryllithium. As is shown in Table XIV, these polymers possess predictable molecular weights, narrow molecular weight distributions, and quantitative degrees of DPE-functionality.

The radical coupling reaction of in-chain-functionalized polymer with a 2.0-fold excess of potassium naphthalenide was carried out in THF at $-78^{\circ} \mathrm{C}$ for $2 \mathrm{~h}$. The results are summarized in Table XV. In each case, the SEC chromatogram of the reaction mixture showed two distinct sharp peaks corresponding to the coupled star product and unreacted precursory DPE-in-chain-functionalized polymer. A typical SEC profile of the reaction mixture is represented in Figure 5(A). When DPE-in-chain-functionalized polystyrene with a $M_{\mathrm{n}}$ of $9.33 \mathrm{~kg} \mathrm{~mol}^{-1}$ was used in the reaction, the coupling product of a four-arm star polymer was obtained in $83 \%$ yield. Under the same conditions, DPE-in-chain-functionalized polystyrene with a $M_{\mathrm{n}}$ of $19.6 \mathrm{~kg} \mathrm{~mol}^{-1}$ was coupled in $77 \%$ yield. Similarly, both DPE-in-chain-functionalized polyisoprene $\left(M_{\mathrm{n}}=21.7 \mathrm{~kg} \mathrm{~mol}^{-1}\right)$ and polystyrene-blockpolyisoprene $\left(M_{\mathrm{n}}=21.3 \mathrm{~kg} \mathrm{~mol}^{-1}\right)$ were coupled in $74 \%$ and $80 \%$ yields, respectively. Thus, the difference of the main chain does not appear to play an observable role in the extent of the radical coupling reaction.

Since all the coupling reactions were not complete, the coupled products were isolated by fractional precipitation to remove their precursor polymers. The isolated polymers possessed sharp monomodal SEC distributions (see Figure 5(B)). Their well-defined architectures of the resulting four-arm star branched polymers were confirmed from their molecular weights, molecular weight distributions, compositions, and arm numbers determined by SEC, ${ }^{1} \mathrm{H}$ NMR, SLS, VPO, and vis- 
Table XV. Synthesis of star polymers by radical coupling reaction of DPE-in-chain-functionalized polymers with potassium naphthalenide

\begin{tabular}{|c|c|c|c|c|c|c|c|c|}
\hline \multirow{3}{*}{ Yield (\%) } & \multicolumn{8}{|c|}{ Star polymer } \\
\hline & \multirow{2}{*}{ Type $^{\mathrm{a}}$} & \multicolumn{3}{|c|}{$M_{\mathrm{n}}\left(\mathrm{kg} \mathrm{mol}^{-1}\right)$} & \multirow{2}{*}{$\frac{M_{\mathrm{w}}\left(\mathrm{kg} \mathrm{mol}^{-1}\right)}{\mathrm{SLS}}$} & \multirow{2}{*}{$\frac{M_{\mathrm{w}} / M_{\mathrm{n}}}{\mathrm{SEC}}$} & \multicolumn{2}{|c|}{$g^{\prime b}$} \\
\hline & & $\overline{\text { Calcd }}$ & SEC & VPO & & & Exp. & Calcd $^{\mathrm{c}}$ \\
\hline 83 & $\mathrm{~A}_{2} \mathrm{~A}_{2}^{\prime}$ & 19.1 & 16.0 & 20.1 & 20.5 & 1.03 & 0.69 & 0.71 \\
\hline 77 & $\mathrm{~A}_{2} \mathrm{~A}_{2}^{\prime}$ & 38.8 & 36.1 & 39.0 & 41.8 & 1.04 & 0.73 & 0.71 \\
\hline 80 & $\mathrm{~A}_{2} \mathrm{~B}_{2}$ & 40.0 & 43.0 & 40.5 & 41.6 & 1.03 & & \\
\hline
\end{tabular}

${ }^{\mathrm{a}} \mathrm{A}$ and $\mathrm{B}$ are polystyrene and polyisoprene, respectively. ${ }^{\mathrm{b}} \mathrm{In}$ toluene at $35^{\circ} \mathrm{C} .{ }^{\mathrm{c}} g^{\prime}=[(3 f-$ $\left.2) / f^{2}\right]^{0.58} \times[0.724-0.015(f-1)] / 0.724 .{ }^{117}$

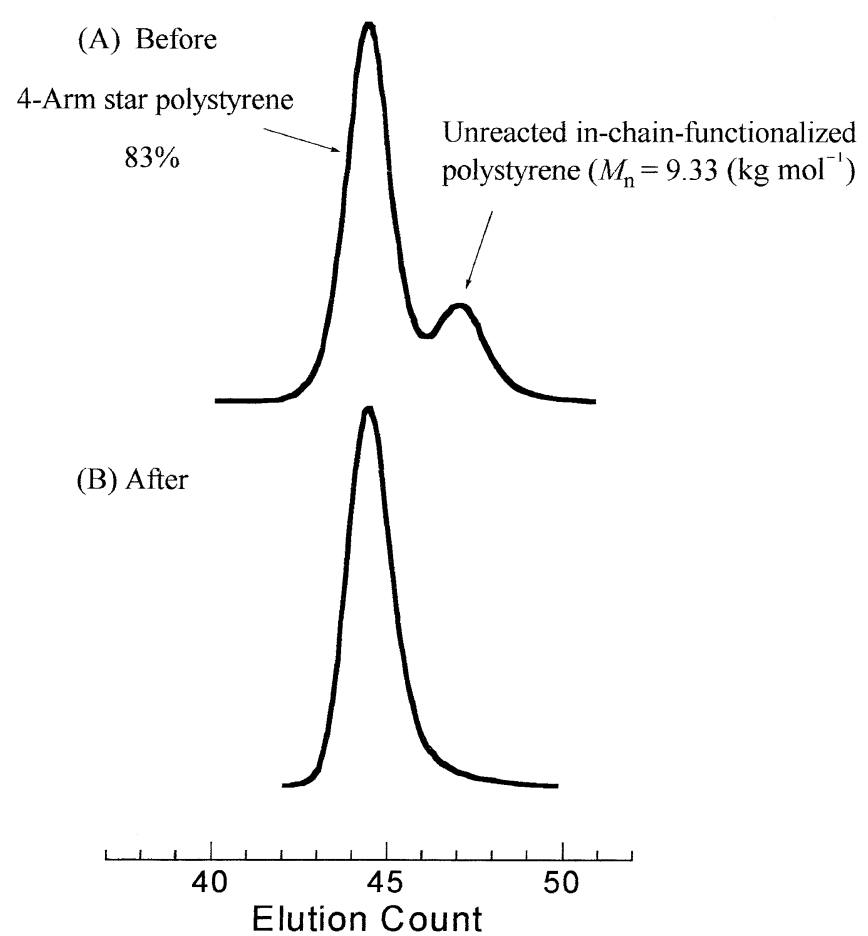

Figure 5. SEC chromatograms of the coupling products before (A) and after (B) SEC fractionation.

cosity measurement ( $g^{\prime}$ value) as were also seen in Table XV.

Thus, the radical coupling reaction of in-chainfunctionalized polymers with DPE moiety with potassium naphthalenide offers a useful method for synthesizing well-defined four-arm regular and $\mathrm{A}_{2} \mathrm{~B}_{2}$ asymmetric star polymers. Since the resulting stars are reactive star polymers with two anions at the cores, they can be used in the iterative reaction sequence in the methodology mentioned bofore. Despite the steric hindrance around the anion, the yields of radical coupling reaction of DPE-in-chain-functionalized polymers were good ( $\sim 80 \%$ yield) and, surprisingly, similar to those of the corresponding DPE-chain-endfunctionalized polymers with nearly equal molecular weights. However, the relative low efficiency of the radical coupling reaction of higher molecular weight DPE-in-chain-functionalized polymers may be predicted from the results of the coupling reaction of chain-end-functionalized polymers with high molecular weights and thereby becoming the major barrier to general development to the star polymer synthesis.

\section{SYNTHESIS OF DENSELY BRANCHED POLYMERS WITH STARLIKE STRUCTURES}

Among branched polymers, the poly(macromonomer)s accessible by living polymerization of well-defined macromonomers belong to the most interesting class of branched polymers from an architectural point of view, because they are considered as one of the ultimate densely branched polymers that have single branch in each repeating unit of backbone polymer and precisely controlled backbone and branch segments in chain length. ${ }^{123-131}$

It has been believed for a long time that such densely branched polymers cannot be synthesized by means of "grafting-onto" method because of serious steric hindrance of branches. However, Deffieux and Schappacher have recently reported the first successful synthesis of such densely branched polymers by the coupling reaction of poly(2-chloroethyl vinyl ether) with polystyryllithium based on a graftingonto method. ${ }^{132,133}$ Quite surprising was that the reaction proceeded in a quantitative manner to introduce polystyrene segment into all repeating units of the poly(2-chloroethyl vinyl ether) under appropriate conditions. More recently, Hirao et al. ${ }^{109,134,135}$ and Hadjichristidis et al. ${ }^{110}$ have also successfully synthesized structurally similar densely branched polymers by the coupling reactions of poly(halomethylstyrene)s with living anionic polymers of styrene and isoprene that are end-capped with DPE. The efficiencies of these reactions were virtually quantitative and any steric limitation was not practically encountered at all. These densely branched polymers possess single branch in every repeating unit and both precisely controlled branch and backbone chains prepared via living polymerizations. Therefore, they are very similar in structure to the poly(macromonomers) obtained by the living polymerization of macromonomers mentioned above. 


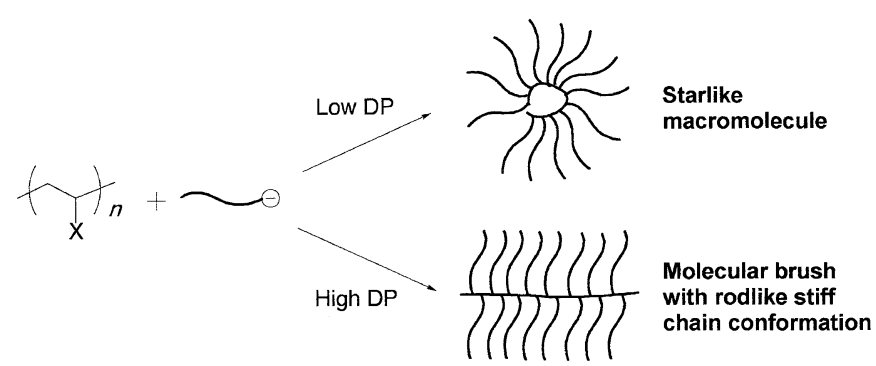

Scheme 15.

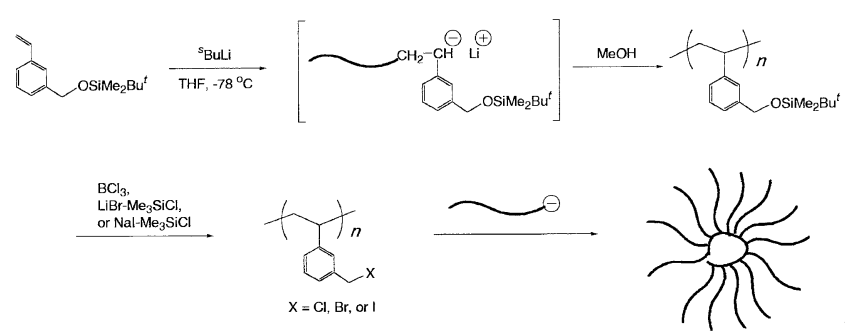

Scheme 16.

The structure of the densely branched polymers, whose backbone chains are much lower in degree of polymerization than branch chains, should be closer to starlike macromolecules rather than molecular brushes with rodlike stiff chain conformation, since the dimensions of the backbone polymer cores are small relative to the outer branches (see Scheme 15). Their arm numbers correspond to the polymerization degrees of the backbone polymers. Thus, the abovementioned methodology for the synthesis of densely branched polymers may also become a convenient synthetic methodology of star polymers. In this chapter, our recent results on this subject have been presented.

\section{Densely Branched Polymers Carrying Single Branch in Every Repeating Unit}

As reactive backbone polymers with precisely controlled chain lengths, poly(3-halomethylstyrene)s were synthesized by a living anionic polymerization of 3tert-butyldimethylsilyloxymethylstyrene (7) and a subsequent transformation reaction into halomethyl functions as illustrated in Scheme 16.

The anionic polymerization of 7 was carried out with sec-BuLi in THF at $-78^{\circ} \mathrm{C}$ for $0.5 \mathrm{~h}$. On addition of 7 into sec-BuLi, an immediate color change from colorless to orange red, characteristic to the polystyrylanion from 7, was observed and the color appeared to remain unchanged during the polymerization. Three sets of the polymerizations were performed at different monomer to initiator ratios. The results are summarized in Table XVI. SEC profiles of the resulting polymers all showed symmetrical monomodal distributions, their $M_{\mathrm{w}} / M_{\mathrm{n}}$ values being very narrow less than 1.06 as shown in Figure 6 . The observed molecular weights by
Table XVI. Anionic polymerization of 7 in $\mathrm{THF}$ at $-78^{\circ} \mathrm{C}$ for 10-30 min

\begin{tabular}{|c|c|c|c|c|}
\hline \multicolumn{3}{|c|}{$M_{\mathrm{n}}\left(\mathrm{kg} \mathrm{mol}^{-1}\right)$} & $M_{\mathrm{w}}\left(\mathrm{kg} \mathrm{mol}^{-1}\right)$ & $M_{\mathrm{w}} / M_{\mathrm{n}}^{\mathrm{a}}$ \\
\hline$\overline{\text { Calcd }}$ & $\mathrm{SEC}^{\mathrm{a}}$ & ${ }^{1} \mathrm{H}$ NMR & $\begin{array}{c}\text { SLS } \\
\end{array}$ & SEC \\
\hline 8.00 & 8.01 & 8.00 & & 1.04 \\
\hline 12.4 & 12.6 & 12.0 & 12.9 & 1.06 \\
\hline 20.0 & 21.9 & 20.3 & 20.8 & 1.02 \\
\hline
\end{tabular}

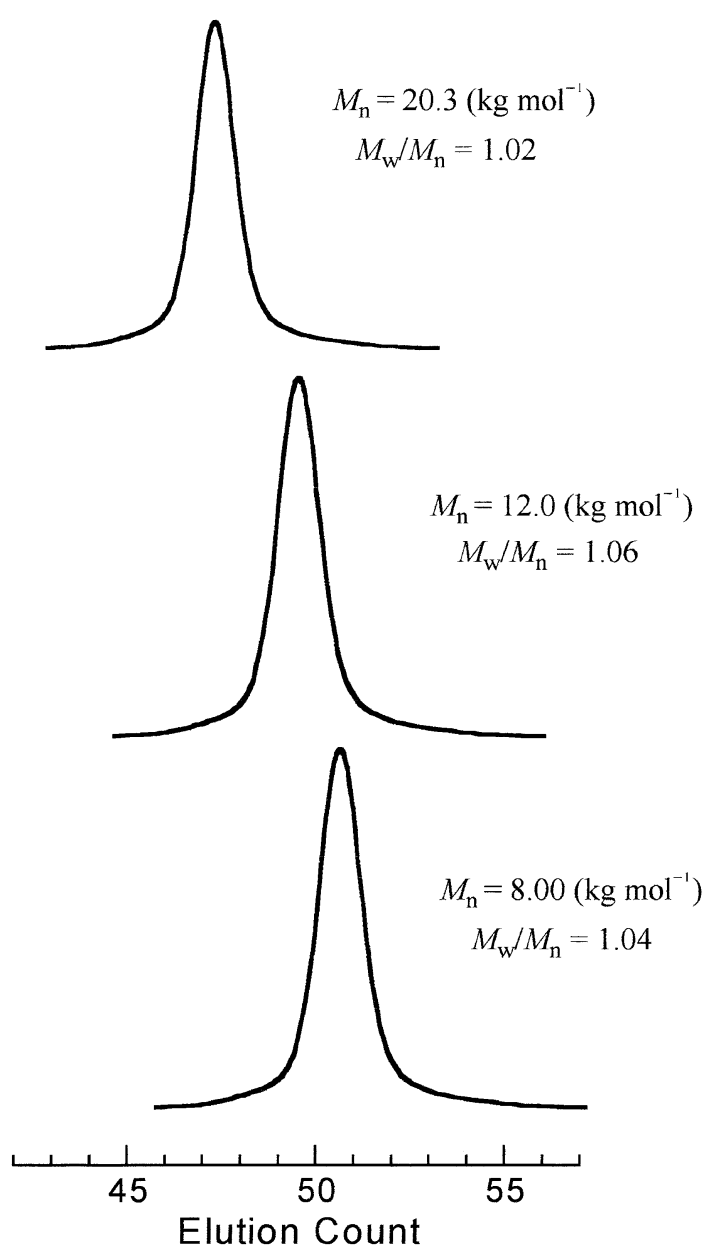

Figure 6. SEC chromatograms of poly(7)s.

${ }^{1} \mathrm{H}$ NMR or SLS were in good agreement with the calculated values. These results as well as red coloration in the system clearly indicate the living character of the anionic polymerization of 7 under the conditions employed.

The tert-butyldimethylsilyloxymethyl group of the resulting poly(7) was transformed into the corresponding chloromethyl, bromomethyl, or iodomethyl group by treatment with $\mathrm{BCl}_{3},\left(\mathrm{CH}_{3}\right)_{3} \mathrm{SiCl}-\mathrm{LiBr}$, or $\left(\mathrm{CH}_{3}\right)_{3} \mathrm{SiCl}-\mathrm{NaI}$. A comparison of SEC profiles of the starting poly(7) and the polymers obtained after the reactions is shown in Figure 7. In each of all samples, the narrowness and monomodal SEC distribution of the starting polymer remained almost unchanged upon the transformation reactions. IR, ${ }^{1} \mathrm{H}$ and ${ }^{13} \mathrm{C} N M R$, and elemental analysis confirmed the expected struc- 


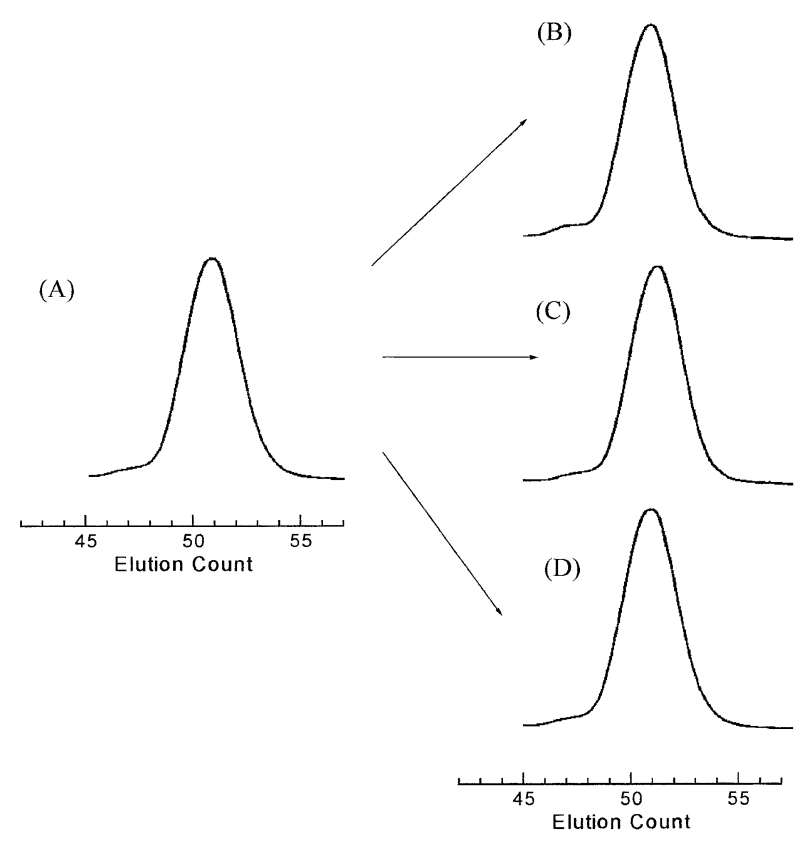

Figure 7. SEC chromatograms of poly(3-halomethylstyrene)s obtained by transformation reactions of poly $(7)\left(M_{\mathrm{n}}=8.00\right.$ $\left.\left(\mathrm{kg} \mathrm{mol}^{-1}\right), M_{\mathrm{w}} / M_{\mathrm{n}}=1.02\right)$ : (A) parent poly(7); (B) poly(3-chloromethylstyrene); (C) poly(3-bromomethylstyrene); (D) poly(3-iodomethylstyrene).

tures of poly(3-halomethylstyrene)s. Thus, poly(3chloromethylstyrene), poly(3-bromomethylstyrene), and poly(3-iodomethylstyrene) with well-defined structures have successfully been synthesized (Table XVII). For the synthesis of densely branched polymers with starlike structures, the poly(3-halomethylstyrene)s with relatively short chains $\left(\mathrm{DP}_{\mathrm{w}}=33, M_{\mathrm{w}} / M_{\mathrm{n}}=1.04\right)$ were usually employed in the next coupling reaction.

Under the conditions in THF at $-40^{\circ} \mathrm{C}$ for $24 \mathrm{~h}$, the poly(3-bromomethylstyrene) $\left(\mathrm{DP}_{\mathrm{w}}=33\right)$ readily coupled in a quantitative manner with DPE-end-capped polystyryllithium (PSDLi) $\left(M_{\mathrm{w}}=8.00 \mathrm{~kg} \mathrm{~mol}^{-1}\right.$, $\mathrm{DP}_{\mathrm{w}}=77$ ). Figure $8(\mathrm{~A})$ shows the SEC chromatogram of the reaction mixture. There are two distinct sharp monomodal SEC peaks corresponding to the expected coupling product and deactivated polystyrene used in excess in the reaction. The objective coupling product isolated by fractional precipitation was pure and free of its branch segment as was seen in Figure 8(B). The results are summarized in Table XVIII.

The molecular weight distribution was narrow, the $M_{\mathrm{w}} / M_{\mathrm{n}}$ value being 1.02 . The $M_{\mathrm{w}}$ value estimated by SEC was much smaller than that calculated as expected from the highly branched structure. The absolute $M_{\mathrm{w}}$ value determined by SLS agreed well with that calculated. Accordingly, the coupling reaction quantitatively proceeded to afford a densely branched polymer carrying single branch in every repeating unit. Similarly, the coupling reaction of poly(3-chloromethylstyrene)
Table XVII. Characterization of poly(3-halomethylstyrene)s

\begin{tabular}{|c|c|c|c|c|c|}
\hline \multirow{2}{*}{ Polymer } & \multicolumn{2}{|c|}{$M_{\mathrm{n}}\left(\mathrm{kg} \mathrm{mol}{ }^{-1}\right)$} & \multirow{2}{*}{$\frac{M_{\mathrm{w}} / M_{\mathrm{n}}}{\mathrm{SEC}}$} & \multicolumn{2}{|c|}{ Functionality $^{\mathrm{a}}$} \\
\hline & Calcd & ${ }^{1} \mathrm{H}$ NMR & & Halogen & $\%$ \\
\hline Poly(7) & 8.00 & 8.01 & 1.04 & & \\
\hline Poly $(\mathrm{CMS})^{\mathrm{b}}$ & 4.95 & 4.94 & 1.04 & $\mathrm{Cl}$ & 100 \\
\hline Poly(BMS) ${ }^{\mathrm{c}}$ & 6.35 & 6.49 & 1.04 & $\mathrm{Br}$ & 100 \\
\hline Poly $(\mathrm{IMS})^{\mathrm{d}}$ & 7.40 & 7.32 & 1.04 & I & 100 \\
\hline
\end{tabular}

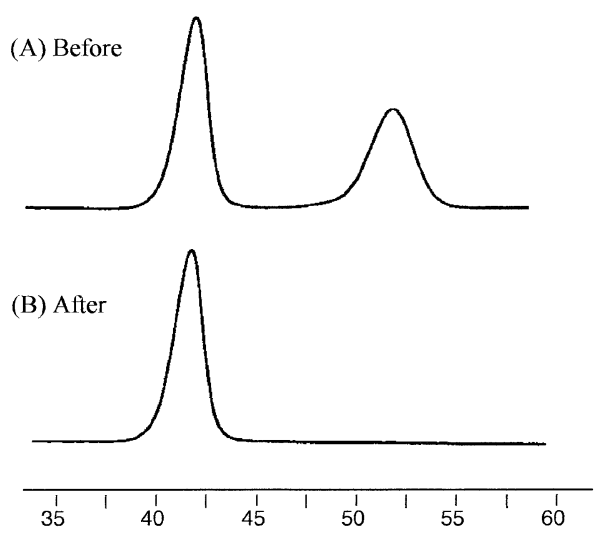

Figure 8. SEC chromatograms of the resulting products obtained by coupling reaction of poly(3-chloromethylstyrene) with PSDLi before (A) and after (B) fractional precipitation.

$\left(\mathrm{DP}_{\mathrm{w}}=33\right)$ with PSDLi $\left(M_{\mathrm{w}}=6.90 \mathrm{~kg} \mathrm{~mol}^{-1}\right.$, $\left.\mathrm{DP}_{\mathrm{w}}=66\right)$ also proceeded in a quantitative manner. In contrast, the reaction of the poly(3-iodomethylstyrene) with PSDLi was not complete along with the formation of a considerable amount ( $\sim 25 \%)$ of dimeric by product under the identical conditions. In this reaction, the possible side reactions such as $\mathrm{Li}-\mathrm{I}$ exchange and single-electron transfer reactions followed by coupling among intermediate polymers were not completely suppressed by end-capping of polystyryllithium with DPE.

Surprisingly, a polystyrenes with a $M_{\mathrm{w}}$ value up to $68.8 \mathrm{~kg} \mathrm{~mol}^{-1}\left(\mathrm{DP}_{\mathrm{w}}=660\right)$ quantitatively coupled with the same poly(3-bromomethylstyrene). Polyisoprenyllithium end-capped with DPE and less reactive living anionic polymers of 2-vinylpyridine and tertbutyl methacrylate also underwent coupling reaction with quantitative efficiency. These results are also summarized in Table XVIII.

As mentioned before, these densely branched polymers are considered to be starlike macromolecules from their structures. In order to ascertain their starbranching structure, the intrinsic viscosities of the three polymer samples consisting of polystyrene chains were measured in toluene at $35^{\circ} \mathrm{C}$ to determine the $g^{\prime}$ values. The overall experimental $g^{\prime}$ values of the three polymer samples were in the range of $0.11-0.16$ as summarized in Table XIX. Assuming that the three samples are star polystyrenes carrying thirty-three arms, the $g^{\prime}$ value can 
Table XVIII. Synthesis of densely branched polymers with starlike structures by coupling reaction of poly(3-halomethylstyrene)s with living anionic polymers

\begin{tabular}{|c|c|c|c|c|c|c|c|c|}
\hline \multicolumn{2}{|c|}{ Backbone } & \multicolumn{2}{|c|}{ Living polymer } & \multicolumn{5}{|c|}{ Branched polymer } \\
\hline & & \multirow{2}{*}{ Type } & \multirow{2}{*}{$\frac{M_{\mathrm{w}}\left(\mathrm{kg} \mathrm{mol}^{-1}\right)}{\mathrm{SEC}}$} & \multicolumn{3}{|c|}{$M_{\mathrm{w}}\left(\mathrm{kg} \mathrm{mol}^{-1}\right)$} & \multirow{2}{*}{$\frac{M_{\mathrm{w}} / M_{\mathrm{n}}}{\mathrm{SEC}}$} & \multirow{2}{*}{$\mathrm{CE}(\%)^{\mathrm{a}}$} \\
\hline náloger & $D r_{w}$ & & & Calcd & SEC & SLS & & \\
\hline $\mathrm{Cl}$ & 33 & PSDLi $^{\mathrm{b}}$ & 8.00 & 267 & 96.0 & 281 & 1.02 & 100 \\
\hline $\mathrm{Cl}$ & 33 & PSDLi & 21.8 & 723 & 230 & 706 & 1.03 & 98 \\
\hline $\mathrm{Br}$ & 33 & PSDLi & 25.2 & 836 & 284 & 877 & 1.02 & 105 \\
\hline $\mathrm{Br}$ & 33 & PSDLi & 68.8 & 2274 & 578 & 2310 & 1.03 & 102 \\
\hline $\mathrm{I}$ & 33 & PSDLi & 6.89 & 231 & 70.0 & 172 & 1.05 & 75 \\
\hline $\mathrm{Br}$ & 33 & $\mathrm{PIDLi}^{\mathrm{c}}$ & 7.30 & 245 & 89.0 & 255 & 1.02 & 104 \\
\hline $\mathrm{Br}$ & 33 & PIDLi & 24.5 & 812 & 315 & 847 & 1.02 & 104 \\
\hline $\mathrm{Cl}$ & 35 & $\mathrm{P} 2 \mathrm{VPLi}^{\mathrm{d}}$ & $6.90^{\mathrm{e}}$ & 246 & 132 & 236 & 1.03 & 96 \\
\hline $\mathrm{Br}$ & 89 & P2VPLi & $16.3^{\mathrm{e}}$ & 1461 & 502 & 1490 & 1.02 & 102 \\
\hline $\mathrm{Br}$ & 89 & $\mathrm{P}\left({ }^{t} \mathrm{BMA}\right) \mathrm{K}^{\mathrm{f}}$ & 31.6 & 2823 & 481 & 2930 & 1.02 & 104 \\
\hline
\end{tabular}

${ }^{\mathrm{a}}$ Coupling efficiency (CE) based on the $M_{\mathrm{w}}$ by SLS. ${ }^{\mathrm{b}} \mathrm{DPE}$-end-capped polystyryllithium. ${ }^{\mathrm{c}} \mathrm{DPE}-$ end-capped polyisoprenyllithium. ${ }^{\mathrm{d}}$ Living anionic polymer of 2-vinylpyridine initiated with ${ }^{s} \mathrm{BuLi}$. ${ }^{\mathrm{e}}$ Calculated by $M_{\mathrm{n}}\left({ }^{1} \mathrm{H} \mathrm{NMR}\right)$ and $M_{\mathrm{w}} / M_{\mathrm{n}}$ (SEC). ${ }^{\mathrm{f}}$ Living anionic polymer of tert-butyl methacryate initiated with diphenylmethylpotassium.

Table XIX. Viscosities and $g^{\prime}$ values of densely branched polystyrenes

\begin{tabular}{|c|c|c|c|c|c|}
\hline \multicolumn{2}{|c|}{$\mathrm{DP}_{\mathrm{w}}$} & \multirow{2}{*}{$\frac{[\eta]_{\text {star }^{\mathrm{a}}}}{\mathrm{dL} \mathrm{g}^{-1}}$} & \multirow{2}{*}{$\frac{[\eta]_{\text {linear }}{ }^{\mathrm{b}}}{{\mathrm{dL} \mathrm{g}^{-1}}}$} & \multicolumn{2}{|c|}{$g^{\prime}$} \\
\hline Backbone & Branch & & & Exp. & Calcd $^{\mathrm{c}}$ \\
\hline 33 & 76 & 0.15 & 0.93 & 0.16 & 0.14 \\
\hline 33 & 209 & 0.25 & 1.79 & 0.14 & 0.14 \\
\hline 33 & 660 & 0.47 & 4.16 & 0.11 & 0.14 \\
\hline
\end{tabular}

${ }^{\mathrm{a}}$ In toluene at $35^{\circ} \mathrm{C} .{ }^{\mathrm{b}} \mathrm{Calculated}$ from $[\eta]=1.26 \times 10^{-4} \mathrm{M}^{0.71}$. ${ }^{\mathrm{c}} \log g^{\prime}=0.36-0.80 \times \log f .{ }^{118}$

be calculated to be 0.14 from the equation proposed by Roovers based on the experimental results. ${ }^{118}$ Thus, agreement between $g^{\prime}$ values observed and calculated is satisfactory in every case. This strongly indicates the starlike structures of the resulting densely branched polymers.

On the basis of these results, the coupling reaction using poly(3-chloromethylstyrene)s or poly(3bromomethylstyrene)s of short chains as cores based on a grafting-onto method has been shown to provide a convenient method for synthesizing star polymers with many arms. The degrees of polymerization of the cores corresponding to the arm numbers are extremely narrowly distributed, but not definite. In a strict sense, the structure of the resulting polymers is not best described as a star polymer with well-defined architecture and relatively less monodisperse than that of star polymers synthesized before. The advantage of this methodology is that the time-consuming synthesis of core materials with many functional groups can be eliminated. It is also advantageous for the large-scale synthesis of star polymers with many arms. Roovers et al., ${ }^{136}$ Deffieux et al., ${ }^{132,133}$ and Hadjichristidis et al. ${ }^{110}$ have reported the same subject on star polymer synthesis mentioned in introduction of this chapter.
Table XX. Synthesis of PS-2Br

\begin{tabular}{|c|c|c|c|c|c|}
\hline \multirow{2}{*}{$\mathrm{DP}_{\mathrm{w}}$} & \multicolumn{3}{|c|}{$M_{\mathrm{n}}\left(\mathrm{kg} \mathrm{mol}^{-1}\right)$} & \multirow{2}{*}{$\frac{M_{\mathrm{w}}\left(\mathrm{kg} \mathrm{mol}^{-1}\right)}{\mathrm{SLS}}$} & \multirow{2}{*}{$\frac{\mathrm{M}_{\mathrm{w}} / \mathrm{M}_{\mathrm{n}}{ }^{\mathrm{a}}}{\mathrm{SEC}}$} \\
\hline & Calcd & $\mathrm{SEC}^{\mathrm{a}}$ & ${ }^{1} \mathrm{H}$ NMR & & \\
\hline 18 & 12.0 & 7.36 & 11.9 & 12.0 & 1.01 \\
\hline 54 & 33.8 & 17.3 & 34.8 & 35.5 & 1.02 \\
\hline 91 & 56.4 & 26.8 & 56.6 & 59.6 & 1.02 \\
\hline
\end{tabular}

${ }^{\mathrm{a}}$ Determined by SEC relative to polystyrene.

\section{Densely Branched Polymers Carrying Two Branches in} Every Repeating Unit

In this section, the synthesis of more densely branched polymers with starlike structures was attempted by the similar coupling reaction using novel functionalized polystyrenes with two benzyl bromide moieties in each monomer unit, PS-2Br. ${ }^{137,138}$ The synthetic outline is illustrated in Scheme 17.

The synthesis of $\mathbf{P S - 2} \mathbf{B r}$ is very similar to that of poly(3-bromomethylstyrene). At first, a new functionalized polystyrene with one benzyl bromide moiety, PS-1Br, was obtained by the living anionic polymerization of 4-[3-(4-tertbutyldimethylsilyloxymethylphenyl)propyl]styrene (8) with sec-BuLi in THF at $-78^{\circ} \mathrm{C}$, followed by treatment with $\left(\mathrm{CH}_{3}\right)_{3} \mathrm{SiCl}-\mathrm{LiBr}$. The resulting PS-1Br was reacted with the functionalized 1,1-diphenylalkyl anion from 4 and sec-BuLi, followed by treatment with $\left(\mathrm{CH}_{3}\right)_{3} \mathrm{SiCl}-\mathrm{LiBr}$ to afford an objective functionalized polystyrene with two benzyl bromide moieties in each monomer unit, PS-2Br. Three polymer samples with different molecular weights were synthesized. The results are summarized in Table XX.

The resulting PS-2Br samples exhibited sharp monomodal SEC distributions without any shoulders and tailings despite the fact that the multistep modified reactions were performed. Their molecular weights de- 

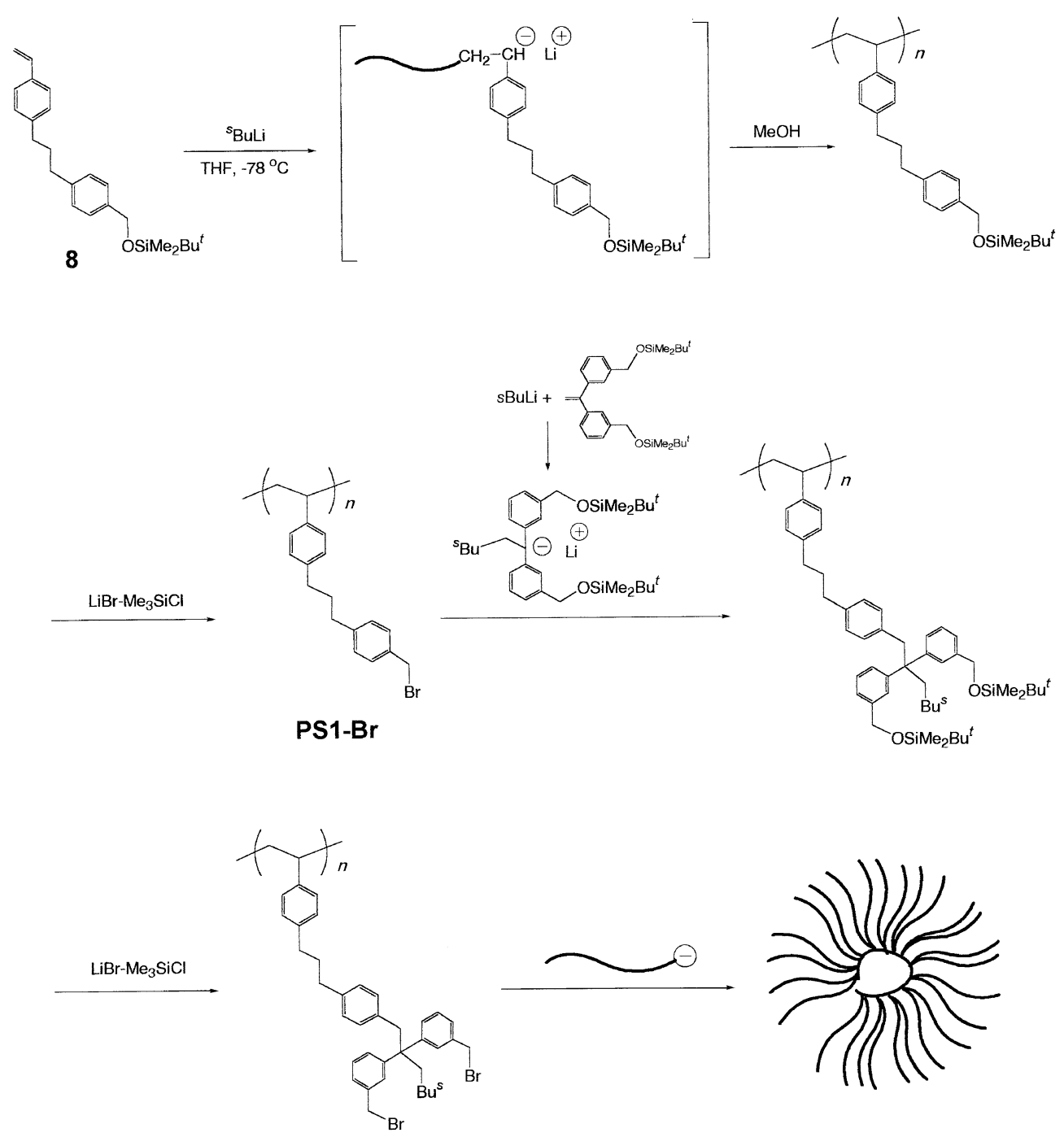

PS2-Br

Scheme 17.

termined by ${ }^{1} \mathrm{H}$ NMR and SLS agreed quite well with those calculated. ${ }^{1} \mathrm{H}$ and ${ }^{13} \mathrm{C}$ NMR, IR, and elemental analysis $(\mathrm{Br} \%)$ analyses confirmed the expected structure of PS-2Br. Thus, a novel well-defined polystyrene with two benzyl bromide moieties in each monomer unit was successfully synthesized. Needless to say, the molecular weight of PS-2Br can be readily controlled at the stage of the living anionic polymerization of $\mathbf{8}$. The PS-2Br sample $\left(\mathrm{DP}_{\mathrm{w}}=18\right)$ having a short chain was employed for the star polymer synthesis. In this sample, the reaction sites are thirty-six in average number.

It is of particular interest to study the coupling reaction of PS-2Br with PSDLi because two benzyl bromide moieties present in every monomer unit as reaction sites appear to be more sterically hindered. Surprisingly, the coupling reaction of $\mathbf{P S}-\mathbf{2} \mathbf{B r}\left(\mathrm{DP}_{\mathrm{w}}=18\right.$, reaction site $=36$ ) with a 1.5 -fold excess of PSDLi $\left(M_{\mathrm{W}}=9.40 \mathrm{~kg} \mathrm{~mol}^{-1}, \mathrm{DP}_{\mathrm{w}}=90\right)$ quantitatively pro- ceeded in THF at $-40^{\circ} \mathrm{C}$ for $1 \mathrm{~h}$. More surprisingly, even a high molecular weight PSDLi with a $M_{\mathrm{w}}$ value of $93.0 \mathrm{~kg} \mathrm{~mol}^{-1}\left(\mathrm{DP}_{\mathrm{w}}=892\right)$ quantitatively coupled with the same PS-2Br. Both DPE-end-capped polyisoprenyllithium and living poly(tert-butyl methacrylate) also underwent coupling reaction with the PS-2Br with quantitative efficiency. Thus, a variety of two polymer chains could be introduced into every repeating unit via two benzyl bromide moieties without any steric limitations by the coupling reaction of the PS-2Br with living anionic polymers. These results are summarized in Table XXI.

The resulting branched polymers may also adopt starlike structures with thirty-six arms. With four branched polystyrene samples thus synthesized, their intrinsic viscosities were measured to determine the $g^{\prime}$ values. These results are listed in Table XXII. The experimental $g^{\prime}$ values were in the range of $0.09-0.15$ and agreed with the calculated value of 0.13 , assum- 
Table XXI. Synthesis of densely branched polymers with starlike structures by coupling reaction of PS-2Br with living anionic polymers

\begin{tabular}{|c|c|c|c|c|c|c|c|}
\hline \multirow{3}{*}{$\frac{\text { Backbone }}{\mathrm{DP}_{\mathrm{w}}(\mathrm{RS})^{\mathrm{a}}}$} & \multicolumn{2}{|c|}{ Living polymer } & \multicolumn{5}{|c|}{ Branched polymer } \\
\hline & \multirow{2}{*}{ Type } & \multirow{2}{*}{$\frac{M_{\mathrm{w}}\left(\mathrm{kg} \mathrm{mol}^{-1}\right)}{\mathrm{SEC}}$} & \multicolumn{3}{|c|}{$M_{\mathrm{w}}\left(\mathrm{kg} \mathrm{mol}^{-1}\right)$} & \multirow{2}{*}{$\frac{M_{\mathrm{w}} / M_{\mathrm{n}}}{\mathrm{SEC}}$} & \multirow{2}{*}{$\mathrm{CE}(\%)^{\mathrm{b}}$} \\
\hline & & & $\overline{\text { Calcd }}$ & SEC & $\overline{\text { SLS }}$ & & \\
\hline $18(36)$ & $\mathrm{PSDLi}^{\mathrm{c}}$ & 9.40 & 351 & 128 & 365 & 1.03 & 104 \\
\hline $18(36)$ & PSDLi & 22.9 & 843 & 293 & 859 & 1.02 & 102 \\
\hline $18(36)$ & PSDLi & 55.1 & 2015 & 628 & 2000 & 1.03 & 99 \\
\hline $18(36)$ & PSDLi & 93.0 & 3394 & 915 & 3490 & 1.01 & 103 \\
\hline $91(182)$ & PSDLi & 9.40 & 1744 & 291 & 1710 & 1.03 & 98 \\
\hline $91(182)$ & $\mathrm{PIDLi}^{\mathrm{d}}$ & 13.3 & 2450 & 444 & 2500 & 1.02 & 98 \\
\hline $91(182)$ & $\mathrm{P}\left({ }^{t} \mathrm{BMA}\right) \mathrm{K}^{\mathrm{e}}$ & 8.12 & 1513 & 216 & 1540 & 1.02 & 102 \\
\hline
\end{tabular}

${ }^{\mathrm{a}}$ Number of reaction site. ${ }^{\mathrm{b}}$ Coupling efficiency (CE) based on the $M_{\mathrm{w}}$ by SLS. ${ }^{\mathrm{c}}$ DPE-end-capped polystyryllithium. ${ }^{\mathrm{d} D P E}$-end-capped polyisoprenyllithium. ${ }^{\mathrm{e}}$ Living anionic polymer of tert-butyl methacrylate initiated with diphenylmethylpotassium.

Table XXII. Viscosities and $g^{\prime}$ values of densely branched polystyrenes

\begin{tabular}{|c|c|c|c|c|c|}
\hline \multicolumn{2}{|c|}{$\mathrm{DP}_{\mathrm{w}}(\mathrm{RS})^{\mathrm{a}}$} & \multirow{2}{*}{$\frac{[\eta]_{\text {star }^{a}}}{\mathrm{dL} \mathrm{g}^{-1}}$} & \multirow{2}{*}{$\frac{[\eta]_{\text {linear }}{ }^{b}}{\mathrm{dL} \mathrm{g}^{-1}}$} & \multicolumn{2}{|c|}{$g^{\prime}$} \\
\hline Backbone & Branch & & & Exp. & Calcd d $^{\mathrm{d}}$ \\
\hline $18(36)$ & 90 & 0.16 & 1.12 & 0.15 & 0.13 \\
\hline $18(36)$ & 219 & 0.30 & 2.06 & 0.14 & 0.13 \\
\hline $18(36)$ & 529 & 0.52 & 3.75 & 0.14 & 0.13 \\
\hline $18(36)$ & 892 & 0.52 & 5.57 & 0.090 & 0.13 \\
\hline
\end{tabular}

${ }^{\mathrm{a}}$ Number of reaction site. ${ }^{\mathrm{b}} \mathrm{In}$ toluene at $35^{\circ} \mathrm{C}$. ${ }^{\mathrm{c}}$ Calculated from $[\eta]=1.26 \times 10^{-4} \mathrm{M}^{0.71} .{ }^{\mathrm{d}} \log g^{\prime}=0.36-0.80 \times \log f .{ }^{118}$

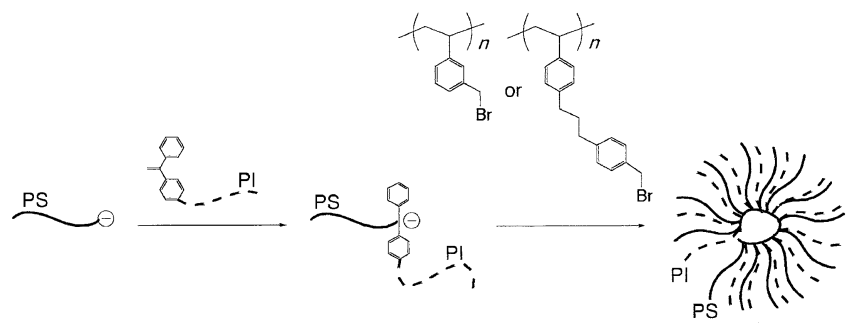

Scheme 18.

ing that they are thirty-six-arm star polymers. Interestingly, there is a remarkable consistency between $g^{\prime}$ values of branched polystyrenes carrying single and two branches. This suggests that the starlike structures of both the branched polymers are very similar. Similar to the reaction using poly(3-halomethylstyrene)s mentioned above, this coupling reaction using PS-2Br also provides a convenient method for the synthesis of star polymers with many arms.

The methodology herein developed has been extended to the synthesis of asymmetric star polymers by the coupling reaction of reactive backbone polymers with polymer anions consisting of different two polymer segments. ${ }^{139}$ The synthetic route is illustrated in Scheme 18. Both poly(3-bromomethylstyrene) and PS$1 \mathrm{Br}$ were used as reactive backbone polymers. The coupling reaction with two kinds of polymer anions consisting of polystyrene (PS) and polyisoprene (PI) was attempted in THF at $-40^{\circ} \mathrm{C}$. Their $M_{\mathrm{w}}$ values were $11.7 \mathrm{~kg} \mathrm{~mol}^{-1}\left(M_{\mathrm{w}}(\mathrm{PS})=5.50 \mathrm{~kg} \mathrm{~mol}^{-1}\right.$ and $M_{\mathrm{w}}$ $\left.(\mathrm{PI})=6.15 \mathrm{~kg} \mathrm{~mol}^{-1}\right)$ and $25.8 \mathrm{~kg} \mathrm{~mol}^{-1}\left(M_{\mathrm{w}}(\mathrm{PS})=\right.$ $5.50 \mathrm{~kg} \mathrm{~mol}^{-1}$ and $\left.M_{\mathrm{W}}(\mathrm{PI})=20.3 \mathrm{~kg} \mathrm{~mol}^{-1}\right)$, respectively.

The reaction of poly(3-bromomethylstyrene) with these polymer anions was not complete under the conditions even after a longer reaction time to one week. The reaction efficiencies were around $50 \%$. Several attempts failed to achieve quantitative efficiency of this coupling reaction. On the other hand, the coupling reaction of PS-1Br $\left(\mathrm{DP}_{\mathrm{w}}=18\right)$ with the same polymer anions quantitatively proceed in THF at $-40^{\circ} \mathrm{C}$ for $24 \mathrm{~h}$ to simultaneously introduce polystyrene and polyisoprene segments in every repeating unit. The results are summarized in Table XXIII. The resulting polymers exhibited sharp monomodal SEC distributions and possessed observed $M_{\mathrm{w}}$ values and compositions that agreed with predictable values. The branched polymer thus synthesized can be regarded as 36 -arm $\mathrm{A}_{18} \mathrm{~B}_{18}$ asymmetric star polymers. The presence of the spacer between reactive site and main chain is thus effective by comparing the results of the coupling reactions with poly(3-bromomethylstyrene) with PS-1Br.

\section{CONCLUDING REMARKS}

Although, until now, several well-defined asymmetric star polymers have been synthesized mainly by means of living anionic polymerization, general and systematic methodologies have not well established yet. In addition, most of the star polymers so far synthesized are relatively limited in arm number and chemical composition.

We have herein proposed two new methodologies that permit the general and systematic synthesis of both regular and asymmetric star polymers with welldefined architectures. In the first methodology, various chain-functionalized polymers with a definite num- 
Table XXIII. Synthesis of densely branched copolymers with starlike structures by coupling reaction of PS-2Br with polymer anion consisting of polystyrene and polyisoprene chains

\begin{tabular}{|c|c|c|c|c|c|c|c|c|}
\hline Backbone & \multirow{2}{*}{\multicolumn{3}{|c|}{$\begin{array}{l}\text { Polymer anion } \\
M_{\mathrm{w}}\left(\mathrm{kg} \mathrm{mol}^{-1}\right)^{\mathrm{a}}\end{array}$}} & \multicolumn{5}{|c|}{ Branched polymer } \\
\hline \multirow{2}{*}{$\mathrm{DP}_{\mathrm{w}}$} & & & & \multicolumn{3}{|c|}{$M_{\mathrm{w}}\left(\mathrm{kg} \mathrm{mol}^{-1}\right)$} & \multirow{2}{*}{$\frac{M_{\mathrm{w}} / M_{\mathrm{n}}}{\mathrm{SEC}}$} & \multirow{2}{*}{$\mathrm{CE}(\%)^{\mathrm{b}}$} \\
\hline & $\overline{\mathrm{PSLi}^{\mathrm{c}}}$ & $\mathrm{PID}^{\mathrm{d}}$ & Total & Calcd & SEC & SLS & & \\
\hline 18 & 6.15 & 5.50 & 11.7 & 229 & 92.2 & 239 & 1.02 & 104 \\
\hline 18 & 20.3 & 5.50 & 25.8 & 502 & 192 & 528 & 1.03 & 105 \\
\hline
\end{tabular}

${ }^{\mathrm{a}}$ Determined by SEC. ${ }^{\mathrm{b}}$ Coupling efficiency (CE) based on the $M_{w}$ by SLS. ${ }^{\mathrm{c} P o l y s t y r y l l i t h i u m . ~}{ }^{\mathrm{d}}$ DPEchain-end-functionalized polyisoprene.

ber of benzyl halide moieties has been introduced in the synthesis of star polymers as quite new polymeric coupling agents that can be intentionally and extensively designed and synthesized. These benzyl halidefunctionalized polymers quantitatively reacted with a wide variety of living anionic polymers of styrene, isoprene, 2-vinylpyridine, tert-butyl methacrylate, and ethylene oxide to afford various new well-defined star polymers. In the second methodology, we have proposed a new iterative concept, in which reaction sites can be always regenerated after the synthetic reaction and therefore further reactions can be repeated. With this iterative methodology, star polymers may possibly be successively and, in principle, unlimitedly synthesized. The feasibility of this methodology is strongly indicated by the fact that three-, six-, nine-, twelve-, and fifteen-arm star polymers were successively synthesized by repeating the iteration five times. Both regular and asymmetric star polymers could also be synthesized by changing living anionic polymers at each stage of the iterations. Furthermore, the intermediate star polymers produced at each of the iterations are reactive star polymers having two benzyl bromide moieties or two and three anions at the cores that can undergo further reactions and polymerizations leading to even more complex star polymers.

Finally, we presented a convenient synthesis of star polymers with many arms by means of quantitative nature of the coupling reactions of living anionic polymers with reactive benzyl halide-functionalized backbone polymers used as cores. The resulting densely branched polymers with shorter backbone chains relative to branches can be regarded as star polymers with many arms. Their arm numbers exactly correspond to the numbers of reaction sites of the functionalized backbone polymers.

By combining these methodologies, it is possible to synthesize a variety of asymmetric star polymers with more complex and even almost all kinds of architectures. The present methodologies are also applicable to difunctional living polymers and polymer anions in which anions are located in chains. In such cases, starlinear-star, linear-star-linear, and linear-star-linear-star-
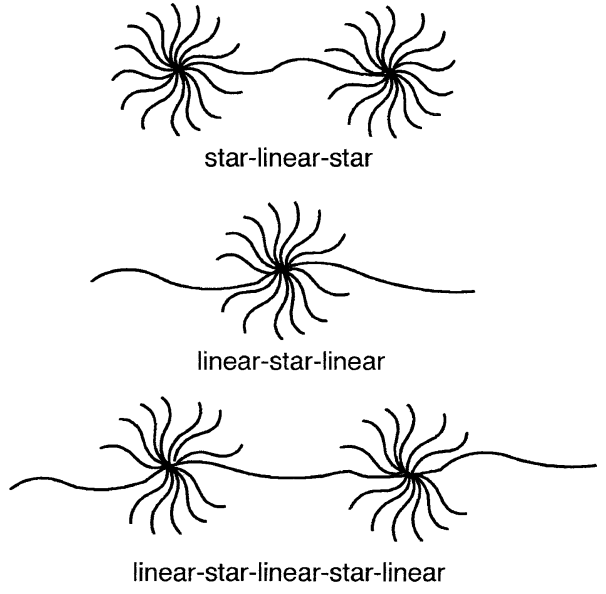

Scheme 19.

linear type polymers will be synthesized as illustrated in Scheme 19.

Many kinds of living anionic polymers of functionalized styrenes, 1,3-dienes, alkyl methacrylates, and some other monomers are now available. Novel asymmetric star polymers consisting of functionalized arm segments in part and/or all arms may possibly be synthesized by employing these living polymers in the proposed methodologies. Topologically functionalized star polymers in which cores are quite different in character from the outer branches can be synthesized by using living anionic functionalized block copolymers of the type AB, ABA, ABC etc. Such star polymers are expected to form self-organized monomolecules or molecular assemblies with three-dimensional ordered structures that can be controlled by the structures of star polymers. These well organized macromolecules are attractive and useful building blocks and/or materials for the future nano-ordered technology.

\section{REFERENCES}

1. B. J. Bauer and L. J. Fetters, Rubber Chem. Technol., 51, 406 (1978).

2. S. Bywater, Adv. Polym. Sci., 30, 89, (1979).

3. J. Roovers, Branched Polymers, in "Encyclopedia of Polymer Science and Engineering", 2nd ed, J. I. Kroschwitz, Ed., Wiley-Interscience, New York, N.Y., 1985, vol. 2, pp 478499. 
4. P. Rempp and J. E. Herz, in "Encyclopedia of Polymer Science and Engineering”, 2nd ed, J. I. Kroschwitz, Ed., WileyInterscience, New York, N.Y., 1989, Supplement, pp 493506.

5. L. J. Fetters and E. L. Tomas, in "Material Science and Technology", VCH Verlangesellschaft, Weinheim, Germany, 1993, vol. 12, pp 1-31.

6. H. L. Hsieh and R. P. Quirk, "Anionic Polymerization: Principles and Applications", Marcel Dekker, Inc., New York, N.Y., Basel, Hong Kong, 1996, pp 333-368.

7. G. S. Grest, L. J. Fetters, and J. S. Huang, Adv. Chem. Phys., XCIV, 67, (1996).

8. S. P. Meneghetti, P. J. Lutz, and D. Rein, in "Star and Hyperbranched Polymers", M. K. Mishra, and S. Kobayashi, Ed., Marcel Dekker, Inc., New York, N.Y., Basel, Hong Kong, 1999, pp 27-57.

9. M. Pitsikalis, S. Pispas, W. J. Mays, and N. Hadjichristidis, Adv. Polym. Sci., 135, 1 (1998).

10. R. P. Zelinski and C. F. Wofford, J. Polym. Sci., Part A: Polym. Chem., 3, 93 (1965).

11. J. Roovers and S. Bywater, Macromolecules, 5, 384 (1972).

12. J. Roovers and S. Bywater, Macromolecules, 7, 443 (1974).

13. N. Hadjichristidis and J. Roovers, J. Polym. Sci., Polym. Phys. Ed., 12, 2521 (1974).

14. N. Hadjichristidis, A. Guyot, and L. J. Fetters, Macromolecules, 11, 668 (1978).

15. N. Hadjichristidis and L. J. Fetters, Macromolecules, 13, 191 (1980).

16. J. Roovers and P. M. Toporowski, Macromolecules, 14, 1174 (1981).

17. J. Roovers, N. Hadjichristidis, and L. J. Fetters, Macromolecules, 16, 214 (1983).

18. P. M. Toporowski and J. Roovers, J. Polym. Sci., Polym. Chem. Ed., 24, 3009 (1986).

19. M. Pitsikalis, S. Pispas, J. W. Mays, and N. Hadjichristidis, Adv. Polym. Sci., 135, 1 (1998).

20. L. L. Zhou, N. Hadjichristidis, P. M. Toporowski, and J. Roovers, Rubberr Chem. Technol., 65, 303 (1992).

21. J. Roovers, L. L. Zhou, P. M. Toporowski, M. V. Zwan, H. Iatrou, and N. Hadjichristidis, Macromolecules, 26, 4324 (1993).

22. Y. Tselikas, H. Iatrou, N. Hadjichristidis, K. S. Liang, K. Mohanty, and D. J. Lohse, J. Chem. Phys., 105, 2456 (1996).

23. F. L. Beyer, S. P. Gido, Y. Poulos, A. Avgeropoulos, and N. Hadjichristidis, Macromolecules, 30, 2373 (1997).

24. C. Lee, S. P. Gido, M. Pitsikalis, J. W. Mays, N. B. Tan, S. F. Trevino, and N. Hadjichristidis, Macromolecules, 30, 3732 (1997).

25. S. Sioula, N. Hadjichristidis, and E. L. Thomas, Macromolecules, 31, 5272 (1998).

26. S. Sioula, N. Hadjichristidis, and E. L. Thomas, Macromolecules, 31, 8429 (1998).

27. S. Pispas, Y. Poulos, and N. Hadjichristidis, Macromolecules, 31, 4177 (1998).

28. S. Pispas, A. Avgeropoulos, N. Hadjichristidis, and J. Roovers, J. Polym. Sci., Part B: Polym. Phys., 37, 1329, (1999).

29. K. Chrissopoulou, S. Harville, S. H. Anastasiadis, G. Fytas, J. W. Mays, and N. Hadjichristidis, J. Polym. Sci., Part B:
Polym. Phys., 37, 3385, (1999).

30. K. Chrissopoulou, Y. Tselikas, S. H. Anastasiadis, G. Fytas, A. N. Semenov, G. Fleischer, N. Hadjichristidis, and E. L. Thomas, Macromolecules, 32, 5115 (1999).

31. S. Pispas, N. Hadjichristidis, I. Potemkin, and A. Khokhlov, Macromolecules, 33, 1741 (2000).

32. D. M. A. Buzza, A. H. Fzea, J. B. Allgaier, R. N. Young, R. J. Hawkins, I. W. Hamley, T. C. B. McLeich, and T. P. Lodge, Macromolecules, 33, 8399 (2000).

33. H. Hückstädt, A. Göpfert, and V. Abetz, Macromol. Chem. Phys., 201, 296 (2000).

34. H. Xie and J. Xia, Macromol. Chem., 188, 2543 (1987).

35. R. W. Pennisi and L. Fetters, Macromolecules, 21, 1094 (1988).

36. J. W. Mays, Polym. Bull., 23, 247 (1990).

37. H. Iatrou and N. Hadjichristidis, Macromolecules, 25, 4649 (1992).

38. H. Iatrou and N. Hadjichristidis, Macromolecules, 26, 2479 (1993).

39. S. J. Wright, R. N. Young, and T. G. Croucher, Polym. Int., 33, 123 (1994).

40. J. Allgaier, R. N. Young, V. Efstratiadis, and N. Hadjichristidis, Macromolecules, 29, 1794 (1996).

41. Y. Tselikas, N. Hadjichristidis, R. L. Lescanec, C. C. Honeker, M. Wohlgemuth, and E. L. Thomas, Macromolecules, 29, 3390 (1996).

42. A. Avgeropoulos, Y. Poulos, N. Hadjichristidis, and J. Roovers, Macromolecules, 29, 6076 (1996).

43. S. Sioula, Y. Tselikas, and N. Hadjichristidis, Macromolecules, 30, 1518 (1997).

44. A. Avgeropoulos and N. Hadjichristidis, J. Polym. Sci., Part A: Polym. Chem., 35, 813 (1997).

45. G. Velis and N. Hadjichristidis, Macromolecules, 32, 534 (1999).

46. V. Bellas, H. Iatrou, and N. Hadjichristidis, Macromolecules, 33, 6993 (2000).

47. T. Fujimoto, H. Zhang, T. Kazawa, Y. Isono, H. Hasegawa, and T. Hashimoto, Polymer, 29, 6076 (1992).

48. H. Hückstädt, V. Abetz, and R. Stadler, Macromol. Rapid Commun., 17, 599 (1996).

49. R. P. Quirk, B. Lee, and L. E. Schock, Makromol. Chem., Macromol. Symp., 53, 201 (1992).

50. R. P. Quirk and T. Yoo, Polym. Bull., 31, 29 (1993).

51. R. P. Quirk, T. Yoo, and B. Lee, J. Macromol. Sci., Pure Appl. Chem., A31, 911 (1994).

52. R. P. Quirk and Y. J. Kim, Polym. Prepr., (Am. Chem. Soc., Div. Polym. Chem.), 37(2), 634 (1996).

53. R. P. Quirk and Y. Tsai, Macromolecules, 31, 8016 (1998).

54. C. M. Fernyhough, R. N. Young, and R. D. Tack, Macromolecules, 32, 5760 (1999).

55. O. Lambert, P. Dumas, G. Hurtrez, and G, Riess, Macromol. Rapid Commun., 18, 343 (1997).

56. O. Lambert, S. Reutenauer, G. Hurtrez, G. Riess, and P. Dumas, Polym. Bull., 40, 143 (1998).

57. S. Reutenauer, G. Hurtrez, and P. Dumas, Macromolecules, 34, 755 (2001).

58. I. M. Khan, Z. Gao, K. Khougaz, and A. Eisenberg, Polym. Bull., 40, 143 (1998).

59. J. P. Kennedy, L. R. Ross, J. E. Lackey, and O. Nuyken, 
Polym. Bull. 4, 67 (1981).

60. H. Shohi, M. Sawamoto, and T, Higashimura, Macromolecules, 24, 4926 (1991).

61. Y. C. Bae and R. Faust, Macromolecules, 31, 2480 (1998).

62. J. Pyun and K. Matyjaszewski, Macromolecules, 33, 217 (2000).

63. J. Ueda, M. Kamigaito, and M. Sawamoto, Macromolecules, 31, 6762 (2000).

64. A. Heise, C. Nguyen, R. Malek, J. L. Hedrick, C. W. Frank, and R. D. Miller, Macromolecules, 33, 2346 (2000).

65. N. Hadjichristidis, S. Pispas, M. Pitsikalis, H. Iatrou, and C. Vlahos, Adv. Polym. Sci., 142, 71 (1999).

66. N. Hadjichristidis, J. Polym. Sci., Part A: Polym. Chem., 37, 857 (1999).

67. N. Hadjichristidis, M. Pitsikalis, S. Pispas, and H. Iatrou, Chem. Rev., 101, 3747 (2001).

68. R. P. Quirk, T. Yoo, Y. Lee, J. Kim, and B. Lee, Adv. Polym. Sci., 153, 67 (2000).

69. R. P. Quirk, Y. Lee, and J. Kim, J. Macromol. Sci., Polym. Rev., C41(4), 369 (2001).

70. B. Charleux and R. Faust, Adv. Polym. Sci., 142, 1 (1999).

71. M. Kamigaito, T. Ando, and M. Sawamoto, Chem. Rev., 101, 3689 (2001).

72. A. Hirao and M. Hayashi, Acta Polym., 50, 219 (1999).

73. A. Hirao, M. Hayashi, and N. Haraguchi, Macromol. Rapid Commun., 21, 1171 (2000).

74. A. Hirao, M. Hayashi, Y. Negishi, Y. Tokuda, T. Higashihara, N. Haraguchi, and A. Matsuo, Kobunsikako (Polymer Apprication) (Japanese), 50, 510 (2001).

75. J. G. Zilliox, P. Remmp, and J. Parrod, J. Polym. Sci., C, 22, 145 (1968).

76. D. J. Worsfold, J. G. Zilliox, and P. Remmp, Can. J. Chem., 47, 3379 (1969).

77. H. Eschwey, M. Hallensleben, and W. Burchard, Makromol. Chem., 173, 235 (1973).

78. L. K. Bi and L. J. Fetters, Macromolecules, 9, 732 (1976).

79. R. N. Young and L. J. Fetters, Macromolecules, 11, 899 (1978).

80. P. Lutz and P. Rempp, Makromol. Chem., 189, 1051 (1988).

81. P. Rempp, E. Franta, and J. E. Herz, Adv. Polym. Sci., 86, 145 (1988).

82. J. W. Mays, N. Hadjichristidis, and L. J. Fetters, Polymer, 29, 680 (1988).

83. O. Okay and W. Funke, Makromol. Chem., Rapid Commun., 11, 583 (1990).

84. W. Funke and O. Okay, Macromolecules, 24, 2623 (1991).

85. C. Tstsilianis, S. Graff, and P. Rempp, Eur. Polym. J., 27, 243 (1991).

86. V. Efstratiadis, Y. Tselikas, N. Hadjichristidis, J. Li, W. Yunan, and J. W. Mays, Polym. Int., 33, 171 (1994).

87. K. Hatada, T. Kitayama, and O. Vogl, in "Macromolecular Design of Polymeric Material”, Marcel Dekker, Inc., New York, Basel, Hong Kong, 1997, pp 154-155.

88. S. Kanaoka, M. Sawamoto, and Y. Higashimura, Macromolecules, 24, 2309 (1991).

89. H. Deng, S. Kanaoka, M. Sawamoto, and Y. Higashimura, Macromolecules, 29, 1772 (1996).

90. T. M. Marsalco, I. Majoros, and J. P. Kennedy, Polym. Bull., 31, 665 (1993).
91. J. Xia, X. Zhang, and K. Matyjaszewski, Macromolecules, 32, 4482 (1999).

92. X. Zhang, J. Xia, and K. Matyjaszewski, Macromolecules, 33, 2340 (2000).

93. K. Y. Beak, M. Kamigaito, and M. Sawamoto, Macromolecules, 34, 215 (2001).

94. K. Y. Beak, M. Kamigaito, and M. Sawamoto, Macromolecules, 34, 7629 (2001).

95. M. Hayashi, K. Kojima, and A. Hirao, Macromolecules, 32, 2425 (1999).

96. M. Hayashi, Y. Negishi, and A. Hirao, Proc. Jpn. Acad., Ser B., 75, 93 (1999).

97. A. Hirao, M. Hayashi, and Y. Tokuda, Macromol. Chem. Phys., 202, 1606 (2001).

98. A. Hirao, A. Matsuo, K. Morifuji, Y. Tokuda, and M. Hayashi, Polym. Adv. Technol., 12, 680 (2001).

99. A. Hirao and M. Hayashi, Macromolecules, 32, 6450 (1999).

100. A. Hirao, M. Hayashi, Y. Negishi, N. Haraguchi, and S. Loykulnant, Macromol. Symp., (in press).

101. A. Hirao, M. Tohoyama, and S. Nakahama, Macromolecules, 30, 3484 (1997).

102. M. Hayashi and A. Hirao, Macromol. Chem. Phys., 202, 1717 (2001).

103. N. Haraguchi, M. Hayashi, and A. Hirao, Macromol. Symp., 183, 11 (2002).

104. A. Hirao and N. Haraguchi, Macromolecules, 35, 7224 (2002).

105. T. Altares, D. P. Wyman, V. R. Allen, and K. Meyersen, J. Polym. Sci., Part A: Polym. Chem., 3, 4131 (1965).

106. J. C. Meunier and V. R. Leemput, Makromol. Chem., 142, 1 (1971).

107. M. Gauthier and M. Möller, Macromolecules, 24, 4548 (1991).

108. M. Gauthier, M. Möller, and W. Burchard, Macromol. Symp., 77, 43 (1994).

109. S. W. Ryu and A. Hirao. Macromolecules, 33, 4765 (2000).

110. T. Tsoukatos, S. Pispas, and N. Hadjichristidis, Macromolecules, 33, 9504 (2000).

111. A. Hirao, M. Hayashi, and A. Matsuo, Polymer, (in press).

112. M. Nagura, N. Haraguchi, and A. Hirao, Polym. Prepr. Jpn., 51, 188 (2002).

113. W. H. Stockmayer and M. Fixman, Ann. N. Y. Acad. Sci., 57, 334 (1953).

114. B. H. Zimm and R. W. Kilb, J. Polym. Sci, 37, 19 (1959).

115. J. F. Douglas and K. F. Freed, Macromolecules, 17, 1854 (1984).

116. J. F. Douglas and K. F. Freed, Macromolecules, 17, 2344 (1984).

117. J. F. Douglas, J. Roovers, and K. F. Freed, Macromolecules, 23, 4168 (1990).

118. J. Roovers, in "Star and Hyperbranched Polymers", M. K. Mishra and S. Kobayashi, Ed., Marcel Dekker, Inc., New York, N.Y., Basel, 1999, pp 285-341.

119. M. Nakata, Makromol. Chem., 149, 99 (1971).

120. A. Hirao, M. Hayashi, and T. Higashihara, Macromol. Chem. Phys., 202, 3165 (2001).

121. A. Hirao and T. Higashihara, Macromolecules, 35, 7238 (2002).

122. T. Higashihara, M. Hayashi, and A. Hirao, Macromol. Chem. 
Phys., 203, 166 (2002).

123. Y. Tukahara, J. Inoue, Y. Ohta, S. Kohjiya, and Y. Okamoto, Polym. J., 26, 1013 (1994).

124. J. W. Feast, V. C. Gibson, A. F. Johnson, E. Khosravi, and M. A. Mohsin, Polymer, 35, 3542 (1994).

125. S. Breunig, V. Heroguez, Y. Gnanou, and M. Fontanille, Macromol. Symp., 95, 151 (1995).

126. V. Heroguez, Y. Gnanou, and M. Fontanille, Macromol. Rapid Commun., 17, 137 (1996).

127. V. Heroguez, S. Breunig, Y. Gnanou, and M. Fontanille, Macromolecules, 29, 4459 (1996).

128. V. Heroguez, Y. Gnanou, and M. Fontanille, Macromolecules, 30, 4791 (1997).

129. K. Matyjaszewski, K. L. Beers, A. Kern, and S. G. Gaynor, J. Polym. Sci., Part A: Polym. Chem., 36, 823 (1998).

130. S. G. Roos, A. H. E. Müller, and K. Matyjaszewski, Macromolecules, 32, 8331 (1999).

131. K. Matyjaszewski, M. Teodorescu, P. J. Miller, and M. L.
Peterson, J. Polym. Sci., Part A: Polym. Chem. 38, 2440 (2000).

132. M. Schappacher and A. Deffieux, Macromol. Chem. Phys., 198, 3953 (1997).

133. M. Schappacher, C. Billaud, P. Christophe, and A. Deffieux, Macromol. Chem. Phys., 200, 2377 (1999).

134. S. W. Ryu and A. Hirao, Macromol. Chem. Phys., 202, 1727 (2001).

135. A. Hirao, H. Kawano, and S. W. Ryu, Polym. Adv. Technol., 13, 275 (2002).

136. J. Roovers, P. Toporowski, and J. Martin, Macromolecules, 22, 1897 (1989).

137. A. Hirao and S. W. Ryu, Macromol. Symp., (in press).

138. S. W. Ryu, H. Asada, and A. Hirao, Macromolecules, 35, 7191 (2002).

139. S. W. Ryu and A. Hirao, Polym. Prepr., Jpn., 49, 1189 (2000).
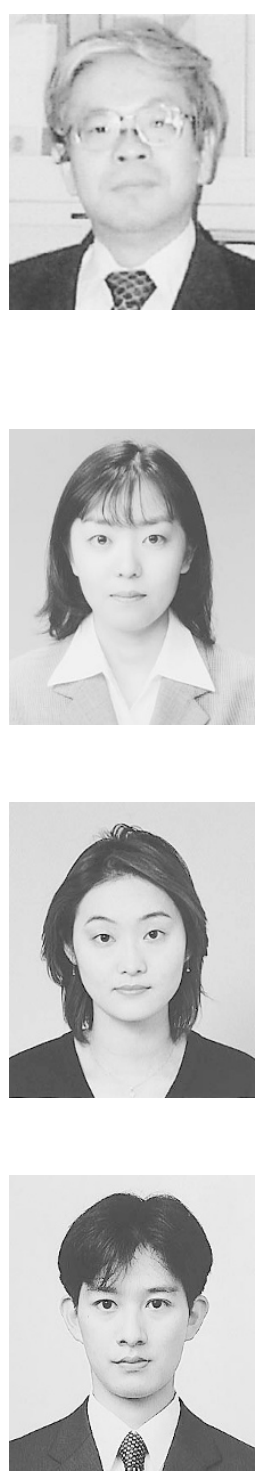

Akira Hirao was born in Tokushima, Japan, in December 4th, 1947. He received his Doctorate Degree from Tokyo Institute of Technology, Japan in 1975. He did postdoctoral research at the University of Alabama, USA, with Professor Charles U. Pittman, Jr. (1975-1977). His carrier at Tokyo Institute of Technology has included being Assistant Professor (1977), Associate Professor (1983), and Full Professor (1997). He has published more than 200 papers in refereed scientific journals and 30 books and reviews. He has made 20 invited lectures at international scientific conferences. His research interest covers living anionic polymerization of functional monomers and precise synthesis of specially shaped polymers, densely branched polymers, and chain-multifunctionalized polymers with well-defined structures by means of living anionic polymerization.

Mayumi Hayashi was born in Kanagawa, Japan, in 1971. She received her Bachelor (1995), Master (1997) and Doctorate degrees (2000) in polymer chemistry under the supervision of Professor Akira Hirao at Tokyo Institute of Technology, Japan, where she received a Research Fellowship for Young Scientists of the Japan Society for the Promotion of Scientists (1998-2000). She joined Sumitomo Chemical Co., Ltd, Japan in 2000 and is currently a researcher in Petrochemicals Research Laboratory. She has published 18 papers in refereed scientific journals and 4 reviews. Her research interest covers precise synthesis of chain-functionalized polymers and star polymers by means of living anionic polymerization.

Yui Tokuda was born in Kanagawa, Japan, in 1976. She received her Bachelor (2000) and Master degrees (2002) in polymer chemistry under the supervision of Professor Akira Hirao at Tokyo Institute of Technology, Japan. She is currently a researcher in Canon Co., Ltd, Japan. She has published 3 papers in refereed scientific journals and one review. Her research interest covers anionic synthesis of well-defined star and densely branched polymers.

Naoki Haraguchi was born in 1974 in Saitama, Japan. He received his Bachelor (1998) and Master (2000) degrees in polymer chemistry at Tokyo Institute of Technology, Japan. He is currently a doctor course graduate student at Tokyo Institute of Technology and doing research on anionic synthesis of well-defined multi-functionalized polymers and applications to densely branched polymers under the supervision of Professor Akira Hirao at Tokyo Institute of Technology where he receives a Research Fellowship for Young Scientists of the Japan Society for the Promotion of Scientists (2002-). 


\section{A. HIRAO et al.}
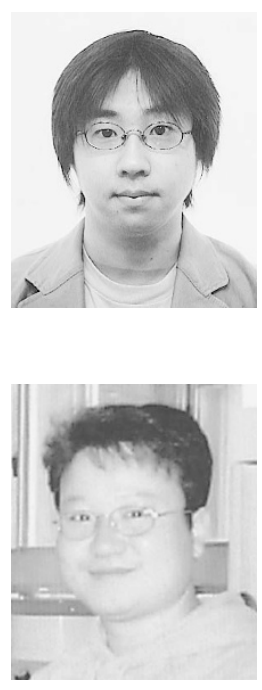

Tomoya Higashihara was born in Kagawa, Japan, in 1977. He received his Bachelor (2000) and Master degrees (2002) in polymer chemistry at Tokyo Institute of Technology, Japan. He is currently a doctor course graduate student at Tokyo Institute of Technology and doing research on synthesis of well-defined asymmetric star polymers by novel iterative methodologies based on living anionic polymerization under the supervision of Professor Akira Hirao at Tokyo Institute of Technology.

Sang-Woog Ryu was born in 1970 in Taegu, Korea. He served in the Army of the Republic of Korea from 1990 to 1992. He received his Bachelor degree (1996) in Industrial Chemistry from Yeungnam University and Master degree (1998) in Materials Science and Engineering from Kwangju Institute of Science and Technology in Korea. He joined international graduate school at Tokyo Institute of Technology in Japan in 1998 and performed research in living anionic polymerization for densely branched comb-like polymers under the direction of Professor Akira Hirao. He obtained his Doctorate degree in 2001 and then joined the laboratory of Professor Anne M. Mayes at Massachusetts Institute of Technology as a postdoctoral associate. He currently works in a field of polymer electrolytes for rechargeable lithium batteries. He has published 6 papers in refereed scientific journals. His research activity is focused on living anionic polymerization of isocyanate monomers, molecular design and synthesis of new densely branched polymers and novel functional block copolymers by living anionic and radical polymerization. 